\title{
Nano-hygroscopicity tandem differential mobility analyzer (nano-HTDMA) for investigating hygroscopic properties of sub-10 $\mathrm{nm}$ aerosol nanoparticles
}

\author{
Ting Lei ${ }^{1,2}$, Nan Ma ${ }^{4,1,3}$, Juan Hong ${ }^{4,1}$, Thomas Tuch ${ }^{3}$, Xin Wang ${ }^{2}$, Zhibin Wang ${ }^{5}$, Mira Pöhlker ${ }^{2}$, Maofa Ge ${ }^{6}$, \\ Weigang Wang ${ }^{6}$, Eugene Mikhailov ${ }^{7}$, Thorsten Hoffmann ${ }^{8}$, Ulrich Pöschl ${ }^{2}$, Hang Su$^{2}$, Alfred Wiedensohler ${ }^{3}$, and \\ Yafang Cheng ${ }^{1}$ \\ ${ }^{1}$ Minerva Research Group, Max Planck Institute for Chemistry, 55128 Mainz, Germany \\ ${ }^{2}$ Multiphase Chemistry Department, Max Planck Institute for Chemistry, 55128 Mainz, Germany \\ ${ }^{3}$ Leibniz Institute for Tropospheric Research, 04318 Leipzig, Germany \\ ${ }^{4}$ Institute for Environmental and Climate Research, Jinan University, 511443 Guangzhou, China \\ ${ }^{5}$ Research Center for Air Pollution and Health, College of Environmental and Resource Science, \\ Zhejiang University, 310058 Hangzhou, China \\ ${ }^{6}$ Beijing National Laboratory for Molecular Sciences (BNLMS), Institute of Chemistry, \\ Chinese Academy of Sciences, 100190 Beijing, China \\ ${ }^{7}$ St. Petersburg State University, 199034 St. Petersburg, Russia \\ ${ }^{8}$ Institute of Inorganic Chemistry and Analytical Chemistry, Johannes Gutenberg University Mainz, 55128 Mainz, Germany
}

Correspondence: Yafang Cheng (yafang.cheng@mpic.de), and Juan Hong (juanhong0108@jnu.edu.cn)

Received: 29 March 2020 - Discussion started: 14 April 2020

Revised: 16 August 2020 - Accepted: 18 August 2020 - Published: 20 October 2020

\begin{abstract}
Interactions between water and nanoparticles are relevant for atmospheric multiphase processes, physical chemistry, and materials science. Current knowledge of the hygroscopic and related physicochemical properties of nanoparticles, however, is restricted by the limitations of the available measurement techniques. Here, we present the design and performance of a nano-hygroscopicity tandem differential mobility analyzer (nano-HTDMA) apparatus that enables high accuracy and precision in hygroscopic growth measurements of aerosol nanoparticles with diameters less than $10 \mathrm{~nm}$. Detailed methods of calibration and validation are provided. Besides maintaining accurate and stable sheath and aerosol flow rates $( \pm 1 \%)$, high accuracy of the differential mobility analyzer (DMA) voltage $( \pm 0.1 \%)$ in the range of $\sim 0-50 \mathrm{~V}$ is crucial for achieving accurate sizing and small sizing offsets between the two DMAs $(<1.4 \%)$. To maintain a stable relative humidity $(\mathrm{RH})$, the humidification system and the second DMA are placed in a well-insulated and air conditioner housing $( \pm 0.1 \mathrm{~K})$. We also tested and discussed different ways of preventing predeliquescence in
\end{abstract}

the second DMA. Our measurement results for ammonium sulfate nanoparticles are in good agreement with Biskos et al. (2006b), with no significant size effect on the deliquescence and efflorescence relative humidity (DRH and ERH, respectively) at diameters down to $6 \mathrm{~nm}$. For sodium sulfate nanoparticles, however, we find a pronounced size dependence of DRH and ERH between 20 and $6 \mathrm{~nm}$ nanoparticles.

\section{Introduction}

The climatic effects of aerosol nanoparticles have attracted increasing interest in recent years (Wang et al., 2016; Andreae et al., 2018; Fan et al., 2018). Interactions between water and nanoparticles are relevant for atmospheric multiphase processes, physical chemistry, and materials science (Zheng et al., 2015, 2020; Cheng et al., 2015, 2016; Su et al., 2020). Aerosol nanoparticles in the atmosphere mostly originate from new particle formation, and a fraction of these nanoparticles could potentially grow into sizes that enable them to ef- 
ficiently act as cloud condensation nuclei and, thus, to change the contributions of aerosol nanoparticles to climate forcing (Lihavainen, 2003; Wiedensohler et al., 2009; Sihto et al., 2011; Kirkby et al., 2011; Keskinen et al., 2013; Dunne et al., 2016; Kim et al., 2016). These processes strongly depend on the chemical composition and physicochemical properties of these nanoparticles (Köhler, 1936; Su et al., 2010; Wang et al., 2015; Cheng et al., 2015). One of the most important physicochemical properties of nanoparticles is their hygroscopic behavior, which describes their ability to take up water, and it can differ significantly from that of larger particles (Hämeri et al., 2000, 2001; Gao et al., 2006; Biskos et al., 2006a, b, c; Cheng et al., 2015).

To understand and predict the hygroscopic properties of nanoparticles, current thermodynamic models mostly rely on the concentration-dependent thermodynamic properties (such as water activity and interfacial energy) derived from the measurements of large aerosol particles or even bulk samples (Tang and Munkelwitz, 1994; Tang, 1996; Pruppacher and Klett, 1997; Clegg et al., 1998). They are thus difficult or impossible to apply to describe the hygroscopic behavior of sub-10 nm nanoparticles, which can often be supersaturated in concentration compared to bulk solutions (Cheng et al., 2015; Wang et al., 2018). Furthermore, the nanosize effect on these properties may also need to be considered (Cheng et al., 2015). The lack of such data hinders the understanding and accurate simulation of the interaction of water vapor and atmospheric nanoparticles. In addition, by knowing the hygroscopicity of newly formed nanoparticles, one can infer the involving chemical species (e.g., organic ratio) in particle formation and initial growth (Wang et al., 2010), which is otherwise difficult and highly challenging to measure directly (Wang et al., 2010; Ehn et al., 2014). Hence, measuring the hygroscopicity of nanoparticles is essential for improving our understanding of aerosol formation, transformation, and their climate effects.

Different techniques have been employed to characterize the hygroscopic properties of aerosol particles in different sizes (Fig. S1 in the Supplement; Tang et al., 2019), such as the Fourier transform infrared spectrometer (FTIR; Zhao et al., 2006), Raman spectroscopy (Dong et al, 2009), electrodynamic balance (EDB; Chan and Chan, 2003, 2005; Chan et al., 2008), optical tweezers (Reid et al., 2011; Rickards et al., 2013), a hygroscopicity tandem differential mobility analyzer (HTDMA; e.g., Rader and McMurry, 1986; Mikhailov et al., 2004, 2008, 2009; Biskos et al., 2006a, b, c; Cheng et al., 2008, 2009; Eichler et al., 2008; Stock et al., 2011; Hong et al., 2014, 2015; Lei et al., 2014; 2018; Mikhailov and Vlasenko, 2020), and atomic force microscopy (AFM; Estillore et al., 2017; Wang et al., 2020). Using these techniques, most of the early laboratory studies focused on the hygroscopic behavior of particles in the accumulation modes and supermicron size range, including deliquescence, efflorescence of pure components, and the effect of organics on the change or suppression of the deliquescence and efflorescence of these inorganic components in mixtures.

For nanoparticles with diameters down to sub-10 nm, there are, however, only very few studies that have attempted to investigate their interactions with water molecules; these studies mainly utilized the setup with humidified tandem differential mobility analyzers (DMAs) (Hämeri et al., 2000, 2001; Sakurai et al., 2005; Biskos et al., 2006a, b, c; Giamarelou et al., 2018). In Table $S 1$ in the Supplement, we summarized the measured DRH and ERH of ammonium sulfate nanoparticles in the size range from 6 to $100 \mathrm{~nm}$, using HTDMAs. In the aforementioned studies, the results of the observed DRH and ERH and prompt or nonprompt phase transitions of ammonium sulfate nanoparticles, however, do not show universal agreement. The technical challenges in HTDMA measurements, especially in the sub-10 nm size range, mainly relate to the (1) accurate sizing and small sizing offset of the two DMAs and (2) highly stable measurement conditions in the whole system. A large sizing offset between the two DMAs may lead to significant errors in the measured growth factor based on error propagation (Mochida and Kawamura, 2004). Massling et al. (2011) and Zhang et al. (2016) suggested that, to achieve good hygroscopic growth factor of nanoparticles, the sizing offset of the two DMAs should be within $\pm 2 \%-3 \%$, which is, however, very difficult to maintain for the sub- $10 \mathrm{~nm}$ size range. To accurately measure phase transition (e.g., DRH and ERH), a highly stable measurement condition is essential, especially for maintaining a small temperature perturbation in the humidification system and inside the second DMA to prevent predeliquescence. For example, a $0.8 \mathrm{~K}$ fluctuation in the experimental temperature during the measurement can result in a $4 \%$ difference in relative humidity $(0 \%-90 \%)$ inside the humidified DMA (Hämeri et al., 2000), leading to an inaccurate determination of the phase transition. Another problem is the prompt versus nonprompt phase transition. Although the effects of impurities on the phase transition of aerosol nanoparticles (Biskos et al., 2006a; Russell and Ming, 2002) may be one possible reason for the previously observed nonprompt phase transitions (e.g., Hämeri et al., 2000), the apparent nonprompt phase transition of aerosol nanoparticles has been thought to be mainly due to the inhomogeneity of relative humidity (RH) and temperature in the humidified DMA during measurements (Biskos et al., 2006b; Bezantakos et al., 2016). Moreover, the hygroscopic measurements are, in general, difficult for nanoparticles with diameters below $20 \mathrm{~nm}$ due to high diffusion losses of nanoparticles (Seinfeld and Pandis, 2006).

In this study, we present the design of a nano-HTDMA setup that enables high accuracy and precision in the hygroscopic growth measurements of aerosol nanoparticles with diameters less than $10 \mathrm{~nm}$. Detailed methods of calibration and validation are provided. We discuss in detail how to maintain the good performance of the system by minimizing uncertainties associated with the stability and accuracy of $\mathrm{RH}$, temperature, voltage for nanoparticle classification, and 
sheath and aerosol flows in the DMA systems. We then apply the nano-HTDMA system to study the size dependence of the deliquescence and the efflorescence of aerosol nanoparticles of two specific inorganic compounds (e.g., ammonium sulfate and sodium sulfate) for sizes down to $6 \mathrm{~nm}$.

\section{Methods}

\subsection{Nano-HTDMA system}

We designed a nano-HTDMA system to measure the aerosol nanoparticle hygroscopic growth factor $\left(g_{\mathrm{f}}\right)$, especially aiming for accurate measurements of the phase transition and hygroscopic growth factor for nanoparticles in the sub- $10 \mathrm{~nm}$ size range. Here, $g_{\mathrm{f}}$ is defined as the ratio of the mobility diameters of nanoparticles after humidification $\left(D_{\mathrm{m}}(\mathrm{RH})\right)$ to those in the dry condition $\left(D_{\mathrm{m}}(<10 \% \mathrm{RH})\right)$; see Sect. S1 and Eq. S1 in the Supplement. As presented in Fig. 1, the nano-HTDMA is comprised of three main components, including two nano-differential mobility analyzers (nanoDMA; TROPOS model; Vienna-type short DMA; Birmili et al., 1997), an ultrafine condensation particle counter (CPC; TSI; model no. 3776), and a humidification system. Table 1 shows the technical specification, where the DMA system, humidification system, and temperature system of the three HTDMA setups are compared to the systems of Biskos et al. (2006b), Hämeri et al. (2000), and this study.

In our setup (Fig. 1), the first nano-DMA (nano-DMA1) is used to produce quasi-monodisperse nanoparticles at a desired dry diameter. The flow rate of the closed-loop sheath flow in the nano-DMA1 is maintained at $10 \mathrm{~L} \mathrm{~min}^{-1}$. The ratio of sheath flow to aerosol flow is $10: 1.5$. The sheath flow is dried in parallel to RH below $10 \%$ by two custom-built Nafion dryers (TROPOS; model no. ND.070). The quasimonodisperse nanoparticles produced by nano-DMA1 then enter the humidification system, which can be set to deliquescence mode (from low RH to high RH for measuring deliquescence) or efflorescence mode (from high RH to low RH for measuring efflorescence). In the deliquescence mode, dry nanoparticles are humidified by a Nafion humidifier (NH-1; TROPOS; model no. ND.070; length $60 \mathrm{~cm}$ ) to a target RH. In the efflorescence mode, nanoparticles are first exposed to a high RH condition $(\sim 97 \% \mathrm{RH})$ in a Nafion humidifier (NH2; Perma Pure; model no. MH-110; length $30 \mathrm{~cm}$ ) and then dried to a target $\mathrm{RH}$ through $\mathrm{NH}-1$. The humid flow in the outer tube of NH-1 is a mixture of high-humidity air produced with a custom-built Gore-Tex humidifier and heater (GTHH; TROPOS; inner radius $1.5 \mathrm{~cm}$ and length $30 \mathrm{~cm}$ ) and dry air in variable proportions. To have precise control of the aerosol RH, the flow rates of the humid and dry air are adjusted with a proportional-integral-derivative (PID) system, including two mass flow controllers (MFC; MKS Instruments, Inc.; model no. MF1) and an RH sensor (Vaisala; model no. HMT330) downstream of NH-1.

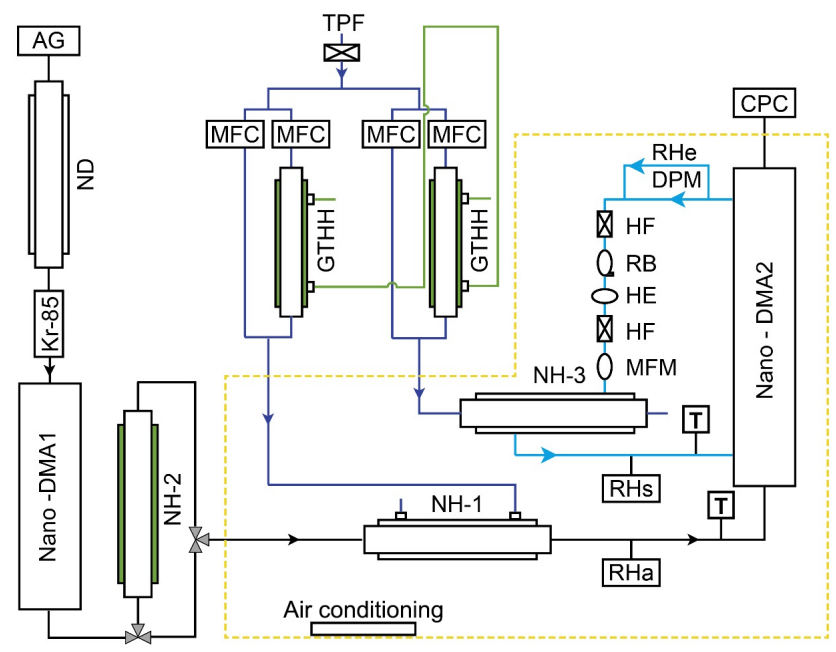

Figure 1. Experimental setup of the nano-HTDMA. Note: AG aerosol generator (aerosol atomizer or electrospray); ND - Nafion dryer; Kr-85 - Krypton source aerosol neutralizer; nano-DMA nano differential mobility analyzer; TPF - total particle filter; HF hydrophobic filter; MFC - mass flow controller; MFM - mass flow meter; RB - recirculation blower; DPM - dew point mirror; GTHH - Gore-Tex humidifier and heater; NH - Nafion humidifier; HE heat exchanger; $\mathrm{CPC}$ - condensation particle counter; black line aerosol line; blue line - sheath line; royal blue line - humidified air; and green line - Milli-Q water (resistivity of $18.2 \mathrm{M} \Omega \mathrm{cm}$ at $298.15 \mathrm{~K}$ ). $\mathrm{RH}_{\mathrm{a}}$ and $\mathrm{RH}_{\mathrm{s}}$ (measured by $\mathrm{RH}$ sensors) represent the relative humidity $(\mathrm{RH})$ of aerosol and sheath flow in the inlet of nano-DMA2, respectively. $\mathrm{RH}_{\mathrm{e}}$ (measured by dew point) represents the RH of excess air. $T$ represents the temperature of aerosol and sheath flow in the inlet of nano-DMA2, respectively.

The residence time is $\sim 5.4 \mathrm{~s}$ in the NH-1 for both the deliquescence and the efflorescence modes. Many groups have reported that the residence time of a few seconds is sufficient for reaching equilibrium to measure the hygroscopic growth or shrink of inorganic salt particles, e.g., ammonium sulfate and chloride sodium (Chan and Chan, 2005; Duplissy et al., 2009; Lei et al., 2014, 2018; Giamarelou et al., 2018). More specifically, Kerminen (1997) estimated the time for reaching the water equilibrium to be between $8 \times 10^{-6}$ and $0.005 \mathrm{~s}$ for $100 \mathrm{~nm}$ nanoparticles at $90 \% \mathrm{RH}$ at $25^{\circ} \mathrm{C}$, with accommodation coefficients from 0.001 to 1 , respectively. In our study, we measured the inorganic aerosol nanoparticles with diameters from $\sim 100 \mathrm{~nm}$ down to $6 \mathrm{~nm}$; thus, the equilibrium time should be even shorter as the nanoparticle size decreases (Table S2). In NH-2, the residence time is $\sim 0.07 \mathrm{~s}$ for the deliquescence of inorganic aerosol nanoparticles at very high $\mathrm{RH}$ conditions ( $~ 97 \% \mathrm{RH})$, which is much longer than the time estimated for the phase transition by Duplissy et al. (2009; of the order of a few milliseconds) and Raoux et al. (2007; of the order of a few nanoseconds). In addition, we have tested a longer NH-2 (Perma Pure; model no. MH-110; length $121 \mathrm{~cm}$ ) in the efflorescence mode, and no significant difference in measured growth factors is found, 
Table 1. Accuracy, precision, and sources of uncertainty associated with HTDMA measurements. Note: GE - general eastern.

\begin{tabular}{|c|c|c|c|}
\hline & Biskos et al. (2006b) & Hämeri et al. (2000) & $\begin{array}{l}\text { Nano-HTDMA } \\
\text { (this study) }\end{array}$ \\
\hline \multicolumn{4}{|l|}{ DMA system } \\
\hline Type of DMA1 and DMA2 & TSI nano-DMAs & Hauke-type DMAs & Vienna-type short DMAs \\
\hline Accuracy of aerosol flow in DMA2 & $\pm 1 \%\left(0.3-1.5 \mathrm{~L} \mathrm{~min}^{-1}\right)$ & - & $\pm 1 \%\left(1.5 \mathrm{~L} \mathrm{~min}^{-1}\right)$ \\
\hline Accuracy of sheath flow in DMA2 & $\pm 1 \%\left(5-15 \mathrm{Lmin}^{-1}\right)$ & - & $\pm 1 \%\left(10 \mathrm{~L} \mathrm{~min}^{-1}\right)$ \\
\hline Accuracy of DMA voltage & $\pm 0.1 \%(0-500 \mathrm{~V})$ & - & $\pm 0.1 \%(0-350 \mathrm{~V})$ \\
\hline $\begin{array}{l}\text { Sizing accuracy of DMA2 } \\
\text { using PSL }\end{array}$ & $3 \%$ & - & $0.4 \%(100 \mathrm{~nm}$ PSL $)$ \\
\hline $\begin{array}{l}\text { Sizing agreement between DMAs } \\
\text { using ammonium sulfate }\end{array}$ & $3.1 \%(10 \mathrm{~nm})^{\mathrm{a}}$ & $\pm 1 \% \mathrm{~b}$ & $\begin{array}{l}0.6 \%(100 \mathrm{~nm})^{\mathrm{c}} \\
0.5 \%(60 \mathrm{~nm})^{\mathrm{c}} \\
1.4 \%(20 \mathrm{~nm})^{\mathrm{c}} \\
0.9 \%(10 \mathrm{~nm})^{\mathrm{c}} \\
-0.2 \%(8 \mathrm{~nm})^{\mathrm{c}} \\
1.4 \%(6 \mathrm{~nm})^{\mathrm{c}}\end{array}$ \\
\hline Precision of particle sizing & $<2 \%$ & - & $<2 \%(6-200 \mathrm{~nm})^{\mathrm{d}}$ \\
\hline \multicolumn{4}{|l|}{ Humidification system } \\
\hline Type of RH sensor & $\begin{array}{l}\text { RH sensors } \\
\text { (Omega; model } \\
\text { no. HX93AV) }\end{array}$ & $\begin{array}{l}\text { Dew point mirror }(\mathrm{GE}) \\
\text { RH sensors } \\
\text { (Vaisala Humitter; } \\
\text { model no. } 50 \mathrm{Y} \text { ) }\end{array}$ & $\begin{array}{l}\text { Dew point mirror (Edgetech) } \\
\text { RH sensors } \\
\text { (Vaisala; model } \\
\text { no. HMT 330) }\end{array}$ \\
\hline $\begin{array}{l}\text { Accuracy of RH sensors } \\
(0 \%-90 \% \text { RH) }\end{array}$ & $\pm 2.5 \% \mathrm{RH}$ & $\pm 3 \% \mathrm{RH}^{\mathrm{e}}$ & $\pm 1 \%$ (RH sensor) \\
\hline Position of the probe in the system & $\begin{array}{l}\text { Inlet of DMA2 } \\
\left(\mathrm{RH}_{\mathrm{a}} \text { sensorf } ; \mathrm{RH}_{\mathrm{s}} \text { sensor }{ }^{\mathrm{g}}\right)\end{array}$ & $\begin{array}{l}\text { Inlet of DMA2 }\left(\mathrm{RH}_{\mathrm{a}} \text { sensor }\right) \\
\text { and excess air }\left(\mathrm{RH}_{\mathrm{s}} \text { sensor; }\right. \\
\text { dew point mirror })\end{array}$ & $\begin{array}{l}\text { Inlet of DMA2 }\left(\mathrm{RH}_{\mathrm{a}} \text { sensor; }\right. \\
\mathrm{RH}_{\mathrm{s}} \text { sensor) and excess air } \\
\text { (dew point mirror) }\end{array}$ \\
\hline RH setting & $\mathrm{RH}_{\mathrm{a}}=\mathrm{RH}_{\mathrm{s}}$ & $\mathrm{RH}_{\mathrm{s}} \geq \mathrm{RH}_{\mathrm{a}}+3 \%$ & $\mathrm{RH}_{\mathrm{a}}=\mathrm{RH}_{\mathrm{s}}$ \\
\hline \multicolumn{4}{|l|}{ Temperature control system } \\
\hline Temperature control type & $\begin{array}{l}\text { Thermally isolated } \\
\text { environment } \\
\text { (humidification and DMA2) }^{\mathrm{h}}\end{array}$ & $\begin{array}{l}\text { Thermally isolated } \\
\text { environment (DMA2) }\end{array}$ & $\begin{array}{l}\text { Box } T \text { regulated } \\
\text { (humidification and DMA2) }\end{array}$ \\
\hline $\begin{array}{l}\text { Difference in } T \\
\text { between inlet and outlet of DMA2 }\end{array}$ & - & - & $<0.2^{\circ} \mathrm{C}$ \\
\hline
\end{tabular}

Note: the "-" shows figures not reported. " According to the scans of the second DMA for the hygroscopic growth of $10 \mathrm{~nm}$ ammonium sulfate and the growth factors at different RHs provided by Biskos et al. (2006b), we retrieved an average sizing offset of the Biskos et al. (2006b) system of $\sim 3.1 \%$ at $10 \mathrm{~nm}$ (see Sect. S1). ${ }^{\mathrm{b}}$ Size range not given. ${ }^{\mathrm{c}}$ See

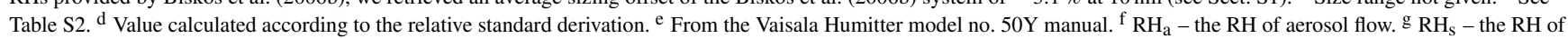
sheath flow. ${ }^{\text {h }}$ Bezantakos et al. (2016).

indicating that the residence time in NH-1 and NH-2 should be sufficient.

The number size distribution of the humidified nanoparticles is measured with a combination of the second nanoDMA (nano-DMA2) and the ultrafine CPC. Similar to Biskos et al. (2016b), a multiple Nafion humidifier (NH-3; Perma Pure; model no. PD-100) is used in our nano-HTDMA system to rapidly adjust the RH of the sheath flow of nano-
DMA2. The sheath flow is fed into the outer tube of the $\mathrm{NH}-3$ to minimize its pressure drop. The RH of humid flow in the inner tube of NH-3 is controlled with a similar PID system to that of NH-1. An RH sensor (Vaisala; model no. HMT330) downstream of NH-3 is used to provide feedback to the PID system. In our nano-HTDMA system, a dew point mirror (DPM; Edgetech; model no: Mirror-99) is placed in the excess flow line to measure the $\mathrm{RH}$ and temperature of 
the excess flow of the nano-DMA2. During the operation, the difference between sheath flow RH and aerosol flow RH was maintained within $\pm 1 \%$ (see more details in Sect. 2.2).

The sheath flow is maintained at the set flow rate with a PID-controlled recirculation blower (RB; Ametek; series Minispiral). Prior to every size scan, the sheath flow rate of the nano-DMA2 is adjusted by the PID system according to the measurement of a mass flow meter (MFM; TSI; series 4000) in the sheath flow line. In order to minimize the pressure drop along the recirculating sheath flow loop, a low flow resistance MFM and hydrophobic filter (HF; Whatman; model no. 6702-3600) are used. A heat exchanger (HE; Ebmpapst; model no. 4414FM) is installed downstream of the RB to minimize the temperature perturbation in the sheath flow by the heat generated in the RB.

As mentioned before, temperature nonuniformity is the main contributor to the fluctuation of RH within humidified DMA. A temperature difference within nano-DMA2 is unavoidable, mainly due to temperature difference between the inner electrode and the rest of nano-DMA2 parts and the temperature difference between aerosol and sheath flow (Duplissy et al., 2009; Bezantakos et al., 2016). As shown in Fig. 1, in order to investigate and monitor the temperature difference within nano-DMA2 during measurements, a temperature sensor (Thermo Electron; model no. Pt100) is placed at the inlet of the sheath flow, and the temperature of sheath excess flow is monitored by the DPM. Note that a DPM should be installed as close as possible to the nano-DMA2 in the excess flow to better represent the conditions inside the nano-DMA2, such as temperature and $\mathrm{RH}$ (Wiedensohler et al., 2012). In addition, the temperature of the aerosol flow is monitored at the inlet of the aerosol flow of nano-DMA2.

Moreover, to maintain a stable environment that is required for the growth factor measurements, a nano-DMA2, with its sheath flow humidification system, is placed in a well-insulated housing chamber (marked with yellow dashed lines in Fig. 1). An air conditioner (Telemeter Electronic $\mathrm{GmbH}$; model no. TEK-1004-RR-24-IP55) is installed inside the housing to maintain a constant temperature $(292.15 \pm$ $0.1 \mathrm{~K}$ ), which is set to be $\sim 1 \mathrm{~K}$ lower than the constant laboratory temperature $(293 \mathrm{~K})$ in order to achieve high RH $(\sim 90 \%)$ inside nano-DMA2.

\subsection{Calibration of nano-HTDMA}

The purpose of this study is to design and build a nanoHTDMA system that is able to measure the hygroscopic properties of nanoparticles, especially in the sub- $10 \mathrm{~nm}$ size range. A small perturbation in the measurement conditions may lead to large biases in the results. Hence, in order to provide high-quality hygroscopicity measurements of nanoparticles, systematic calibration of the nano-HTDMA should be conducted regularly to ensure the accuracy and stability of the measurement conditions. Table 1 lists the possible sources of uncertainty which could affect the performance of the HTDMAs. In our setup, nanoparticle sizing, aerosol and sheath flow rates, the high voltage (HV) applied to nanoDMAs, RH sensors, and temperature sensors are calibrated and verified independently.

Note that in the following, for calibration and checking of different parameters, the criteria and standards that the nanoHTDMA system has to meet are listed mainly according to the suggestions from Duplissy et al. (2009) and Wiedensohler et al. (2012), which are not specifically provided for accurately measuring the size or hygroscopic growth of sub$10 \mathrm{~nm}$ nanoparticles. Compared with these criteria for measuring the hygroscopic growth of sub- $10 \mathrm{~nm}$ nanoparticles, we have achieved a better condition for our nano-HTDMA system after comprehensive calibrations, as described in the following (for more details about the performance of our system see Sect. 3).

\subsubsection{Sizing accuracy}

For particle diameters higher than $100 \mathrm{~nm}$, the verification of the sizing accuracy of DMAs can be accomplished by using certified particles of known sizes, such as polystyrene latex (PSL) spheres (Hennig et al., 2005; Mulholland et al., 2006; Duplissy et al., 2009; Wiedensohler et al., 2012, 2018). The particle sizing of nano-DMA2 is checked with PSL by switching off the sheath flow and the HV supply of nanoDMA1, which actually, in this case, does not function as a DMA but rather a stainless-steel tube. Sizing agreement between measured diameters and nominal diameters of PSL particles above $100 \mathrm{~nm}$ should be within $\pm 3 \%$ (Wiedensohler et al., 2012). After confirming the accurate sizing of nano-DMA2, the sizing accuracy of nano-DMA1 can be, in turn, checked by the nano-DMA2 with a full scan of a certain size of PSL spheres selected by the nano-DMA1. Note that it is important to check not only the sizing accuracy of both DMAs but also the sizing agreement between the nanoDMA1 and nano-DMA2. To achieve good hygroscopicity measurements of nanoparticles, the sizing offset of the two DMAs should be within $\pm 2 \%-3 \%$ (Massling et al., 2011; Zhang et al., 2016).

For nanoparticles with diameters smaller than $100 \mathrm{~nm}$, the sizing accuracy is, however, difficult to check by using PSL nanoparticles. This is mainly because the size of the residual material in the solution also peaks around $20-30 \mathrm{~nm}$ (Fig. S2a), resulting in an asymmetric number size distribution of generated PSL nanoparticles (Fig. S2b; Wiedensohler et al., 2012). PSL nanoparticles with diameters below $20 \mathrm{~nm}$ are not commercially available (https://www. thermofisher.com/order/catalog/product/3020A, last access: 1 April 2020), making verifications in this size range even more impossible. The sizing accuracy of nanoparticles is critically determined by sheath flow rates and HV applied to the nano-DMAs. However, unlike for the $100 \mathrm{~nm}$ nanoparticles, a $\pm 2 \%-3 \%$ sizing offset between the two DMAs would be 
very difficult to maintain for nanoparticles with diameters smaller than $20 \mathrm{~nm}$. Thus, accurate calibrations of the sheath flow rates and $\mathrm{HV}$ are crucial for constraining the uncertainty associated with sizing of nanoparticles below $100 \mathrm{~nm}$. The calibrations for aerosol and sheath flow, DMA voltage, and sensors will be described in detail in Sect. 2.2.2-2.2.5.

\subsubsection{Aerosol and sheath flow}

The sizing accuracy of a DMA directly depends on the accuracy of aerosol and sheath flow rates. The aerosol flow rate at the inlet of the nano-DMA1 is checked by using a bubble flow meter (Gilian; model Gilibrator-2). Wiedensohler et al. (2012) recommended that the measured aerosol flow rate should not deviate by more than $5 \%$ from the set flow rate during the measurements; otherwise, one should check the flow rate of CPC or check if there is a leak in the system. Details about leak checking can be found in Birmili et al. (2016).

To calibrate the sheath flow, a verified MFM (TSI; series 4000) is placed in the recirculating sheath flow closed loop upstream of the MFM. By applying a series of sheath flow rates, a calibration curve (flow rate vs. MFM analog output) can be obtained according to the reading of the reference MFM. A maximum deviation of $2 \%$ from the sheath flow rate value of the reference MFM is recommended by Wiedensohler et al. (2012), which can keep the sizing accuracy of $200 \mathrm{~nm}$ PSL particles within $\pm 2 \%$.

\subsubsection{DMA voltage}

The sizing of nano-DMAs is very sensitive to the accuracy and precision of the voltages applied, especially when measuring nanoparticles in the sub- $10 \mathrm{~nm}$ diameter range. A verified reference voltage meter, with voltage up to $1000 \mathrm{~V}$ (Prema; model no. 5000 DMM; accuracy $0.005 \%$ ), is used to calibrate the HV supply of the nano-DMAs $(0-350 \mathrm{~V})$. By setting a series of analog voltage values, the HV applied to nano-DMA can be calibrated according to the values shown in the reference voltage meter. For our nano-DMAs, sub-10 nm particle sizes correspond to voltage below $50 \mathrm{~V}$. Hence, voltage calibration should be performed with a higher resolution (smaller voltage interval), from 0 to $50 \mathrm{~V}$ (shown in the inset of Fig. 2).

\subsubsection{RH sensor}

One typical method for calibrating RH sensors in a HTDMA system is measuring the hygroscopic growth factors of ammonium sulfate (Hennig et al., 2005), although the effects of shape factors, restructuring, and impurities in the solutions may hamper a reliable $\mathrm{RH}$ calibration with this method (Duplissy et al., 2009). Moreover, this indirect RH sensor calibration through the measurement of the hygroscopic growth factors of ammonium sulfate (usually with nanoparticle diameters around or above $100 \mathrm{~nm}$ ) only calibrates the RH

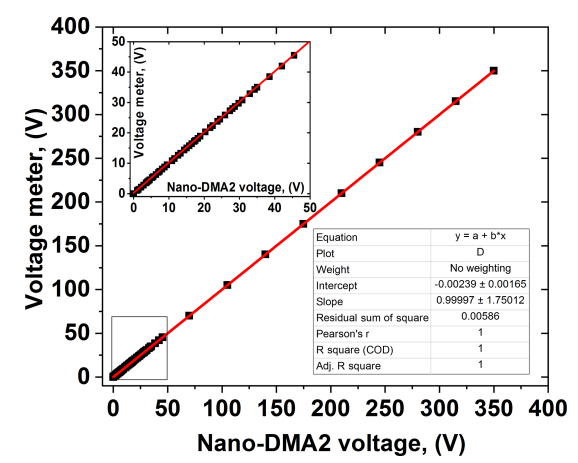

Figure 2. An example of voltage calibration of the nano-DMA2.

values higher than the ERH of the pure salt. Calibration of RHs below the ERH of ammonium sulfate is important for the phase transition measurements. Most importantly, we are investigating the hygroscopic growth factors of ammonium sulfate nanoparticles. Hence, using ammonium sulfate nanoparticles to calibrate RH sensors in our system becomes invalid.

Therefore, we alternatively calibrate the RH sensors by using a DPM (Edgetech; model no. MIRROR-99), which has been recommended in several previous studies (Hennig et al., 2005; Duplissy et al., 2009; Biskos et al., 2006a, b, c). In the calibration, the DPM and RH sensors should be kept in the well-insulated chamber with constant laboratory conditions (e.g., flow rates, temperature, and pressure). By running the DPM and all the other RH sensors in parallel at various RHs ( $5 \%$ to $90 \%$ ), a calibration curve of the RHs measured by the DPM against the analog voltages of RH sensor can be obtained.

\subsubsection{Temperature sensor}

Since all our temperature sensors and the highly accurate DPM (Edgetech; model no. MIRROR-99) are installed in the aforementioned well-insulated chamber, and the chamber temperature is maintained with an air conditioner at about $292.15 \pm 0.1 \mathrm{~K}$, we calibrate the temperature sensors and correct their systematic shift by comparing the record of the temperature sensors and the DPM by keeping them in parallel inside the chamber over a $12 \mathrm{~h}$ time period.

\subsection{Particle generation}

The experiments shown in this study were conducted using laboratory-generated ammonium sulfate and sodium sulfate nanoparticles. Nanoparticles with diameters of 6,8 , and $10 \mathrm{~nm}$ were generated by an electrospray (AG; TSI; model no. 3480) with 1,5 , and $20 \mathrm{mM}$ aqueous solution of ammonium sulfate and sodium sulfate (Sigma-Aldrich; 99.99\%), respectively. The generated particles were then diluted and dried to RH below $2 \%$ by mixing them with dry and filtered $\mathrm{N}_{2}\left(1 \mathrm{~L} \mathrm{~min}^{-1}\right)$ and $\mathrm{CO}_{2}\left(0.1 \mathrm{~L} \mathrm{~min}^{-1}\right)$. The dried poly- 
disperse aerosol nanoparticles were subsequently neutralized by a Po-210 neutralizer. To avoid blocking the $25 \mu \mathrm{m}$ capillary of the electrospray with a high-concentration solution, we used an atomizer (AG; TSI; model no. 3076) to generate nanoparticles with diameters of 60-100 and $20 \mathrm{~nm}$, with a 0.05 and $0.001 \mathrm{wt} \%$ solution of ammonium sulfate and sodium sulfate (Sigma-Aldrich; 99.99\%), respectively. Also, $100 \mathrm{~nm}$ PSL nanoparticles were atomized from a PSL solution by mixing three drops of $100 \mathrm{~nm}$ PSL with $300 \mathrm{~mL}$ distilled and deionized Milli-Q water. The generated nanoparticles were subsequently dried to $\mathrm{RH}$ below $10 \%$ with a custom-built Nafion dryer (ND; TROPOS; model no. ND.070) and then neutralized by a $\mathrm{Kr}^{85}$ neutralizer.

The solutions used in our measurements were prepared with distilled and deionized Milli-Q water (resistivity of $18.2 \mathrm{M} \Omega \mathrm{cm}$ at $298.15 \mathrm{~K}$ ). Note that, for $100-60$ and $20 \mathrm{~nm}$, the solution concentration was adjusted so that the sizes selected by the nano-DMA1 were always larger than the peak diameter of the number size distribution of the generated nanoparticles to minimize the influence of the multiple charged nanoparticles in the hygroscopicity measurements. The influence of multiple charges on sub-10 nm particles is expected to be very small; we, however, still used different concentrations so that the sizes selected by the nano-DMA1 were always around the peak of the number size distribution of the nanoparticles generated by the electrospray (Fig. S3). This was to ensure that we could have as many particles as possible to compensate for the strong loss of very small particles in the whole humidification system.

\section{Results and discussion}

\subsection{Performance of the nano-HTDMA}

\subsubsection{Sizing accuracy}

In this section, we show the performance of our nanoHTDMA after a full calibration, including accuracy and stability of the aerosol and sheath flow rates, the voltage applied to the nano-DMAs, and nanoparticle sizing accuracy. In our study, the sheath and aerosol flow rates and nanoDMA voltage supply have been calibrated every day and every 2 weeks, respectively. The deviations of the measured aerosol and sheath flow rates from the set point values are less than $\pm 1 \%$, which is lower than the maximum variation of $2 \%$ recommended by Wiedensohler et al. (2012).

The voltage applied to the nano-DMAs (up to $350 \mathrm{~V}$ ) is kept within $\pm 0.1 \%$, which is around the set value shown in the voltage meter. As shown in Fig. 3a, when testing with $100 \mathrm{~nm}$ PSL nanoparticles, the average peak diameter of scans from the nano-DMA2 is $100.4 \mathrm{~nm}$, which matches well with the mean diameter of PSL nanoparticles $(100 \pm$ $3 \mathrm{~nm}$; Thermo Fisher Scientific Inc.). Afterwards, when using nano-DMA1 to select $100 \mathrm{~nm}$ PSL, the scanned size dis- tribution by nano-DMA2 has a peak diameter at $100.3 \mathrm{~nm}$ (Fig. 3b), indicating a good sizing accuracy of the nanoDMA1 too. As discussed in Sect. 2.2.1, it is difficult to verify the sizing accuracy of sub-100 $\mathrm{nm}$ aerosol nanoparticles using PSL nanoparticles. Duplissy et al. (2009) and Wiedensohler et al. (2012) suggested estimating the sizing accuracy of sub-100 nm nanoparticles through the DMA transfer function. The theoretical DMA transfer function (see Sect. S2 and Eqs. S2-S4) was proposed by Knutson and Whitby (1975), and they noted that sizing is crucially dependent on flow rates and HV applied to the DMA. In our study, the flow accuracy calibrated by the mass flow meter (TSI; series 4000) is within $\pm 2 \%$. The variation in voltage applied to the nanoDMAs (0-12 500 V, 0-350 V) around the set value was measured with voltage power supply (HCE 0-12500; HCE 0-350; FuG Elektronik) and is summarized in Table S5. According to the error propagation formula (see Sect. 2 and Eq. S5; Taylor and Taylor, 1997), the calculated uncertainty in the sizing of 6-100 nm nanoparticles increases as size decreases (Table S5). The estimated sizing accuracy is slightly smaller than the sizing offset of the two nano-DMAs, but in principle they are still consistent with each other. This suggests that uncertainties in slip correction, DMA dimensions (inner and outer radius and length), temperature, pressure, and viscosity of air may also affect the sizing accuracy (see Sect. S2 and Eq. S4; Kinney et al., 1991). Besides, Wiedensohler et al. (2012) also suggested that particle losses and the sizeand material-dependent CPC counting efficiency can affect the size accuracy of DMAs.

After calibration, on average a $<1.4 \%$ sizing offset between the two nano-DMAs can be achieved for ammonium sulfate nanoparticles with dry diameters of 100,60 , and $20 \mathrm{~nm}$ (Figs. 3c, 5, S4, and S5; Table S3), which is much better than the 2\%-3\% criteria recommended by Massling et al. (2011) and Zhang et al. (2016). For sub-10 nm ammonium sulfate nanoparticles, our system has an average sizing offset of $<0.9 \%$ for 10 and $8 \mathrm{~nm}$ particles and $\sim 1.4 \%$ for $6 \mathrm{~nm}$ particles, respectively (Figs. 3d, 5, and S6; Table S3). As discussed above, uncertainties in the sheath flow rates and nanoDMA voltages will increase as size decreases, which results in a larger sizing offset of $6 \mathrm{~nm}$ nanoparticles compared with other sizes. Note that we also tested the calibration of the DMA voltage with a voltage meter with a lower accuracy of $\pm 1 \%$, and the DMA voltages can only be kept within $\pm 1 \%$ around the set value. In this way, we found a much larger sizing offset for the sub-10 nm particles, i.e., $5.4 \%$ and $6.0 \%$ for 8 and $6 \mathrm{~nm}$ ammonium sulfate nanoparticles, respectively. These results show that maintaining an accurate sheath and aerosol flow (with $\pm 1 \%$ around the set value) together with a careful voltage calibration (with $\pm 0.1 \%$ around the set value, especially in low-voltage range, i.e., $<50 \mathrm{~V}$ for our system) is the key for the accurate sizing of sub-10 $\mathrm{nm}$ nanoparticles. 

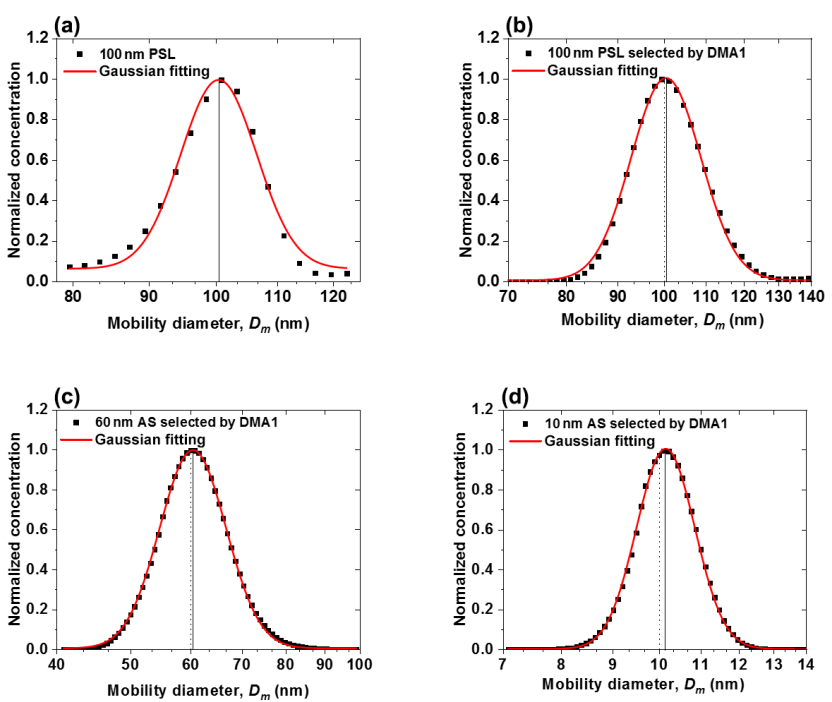

Figure 3. Sizing accuracy and sizing offset of nano-DMAs after calibration. (a) Normalized number size distribution scanned by the nano-DMA2 for $100 \mathrm{~nm}$ PSL nanoparticles (black solid square). Normalized number size distributions scanned by the nano-DMA2 for $100 \mathrm{~nm}$ PSL nanoparticles (b) and $60 \mathrm{~nm}$ (c) and $10 \mathrm{~nm}$ (d) ammonium sulfate (AS) selected by the nano-DMA1 at RH below $5 \%$ at $298 \mathrm{~K}$ (black solid square). The dotted lines mark the diameters of the monodispersed nanoparticles selected by the nano-DMA1, i.e., $100 \mathrm{~nm}$ in (b), $60 \mathrm{~nm}$ in (c), and $10 \mathrm{~nm}$ in (d). The black solid lines mark the peak diameters from the Gaussian fits (red curve).

\subsubsection{Preventing predeliquescence in the deliquescence measurement mode}

Predeliquescence of dry nanoparticles in the deliquescence measurement mode is an important issue that needs to be resolved in order to obtain accurate DRH (Biskos et al., 2006b; Duplissy et al., 2009; Bezantakos et al., 2016; Hämeri et al., 2000). Since temperature and RH are closely linked, and accurate monitoring of these two quantities in the system is critical for nano-HTDMA measurements, we calibrated all $\mathrm{RH}$ and $\mathrm{T}$ sensors regularly (every 2 weeks in this study). To prevent predeliquescence, and to optimize the system, we have conducted three tests using ammonium sulfate nanoparticles with a dry diameter of $100 \mathrm{~nm}$. In the first test, we regulated the $\mathrm{RH}$ of the excess flow $\left(\mathrm{RH}_{\mathrm{e}}\right)$ and made it equal to that of the aerosol flow at the inlet of nano-DMA2 $\left(\mathrm{RH}_{\mathrm{a}}\right)$, i.e., $\mathrm{RH}_{\mathrm{e}}=\mathrm{RH}_{\mathrm{a}}$, as done by previous HTDMA measurements (e.g., Villani et al., 2008). As shown in Fig. 4a, the measured growth factors of $100 \mathrm{~nm}$ ammonium sulfate are in good agreement with predictions of the Extended Aerosol Inorganics Model (E-AIM; Clegg et al., 1998) at RH above $80 \%$. However, the ammonium sulfate nanoparticles deliquesce at $75 \% \mathrm{RH}$, which is significantly lower than the expected DRH (80\%; Tang and Munkelwitz, 1994). Since our RH sensors were all well calibrated, and the uncertainty of $\mathrm{RH}$ measurement is $\pm 1 \%$, it is reasonable to hypothesize
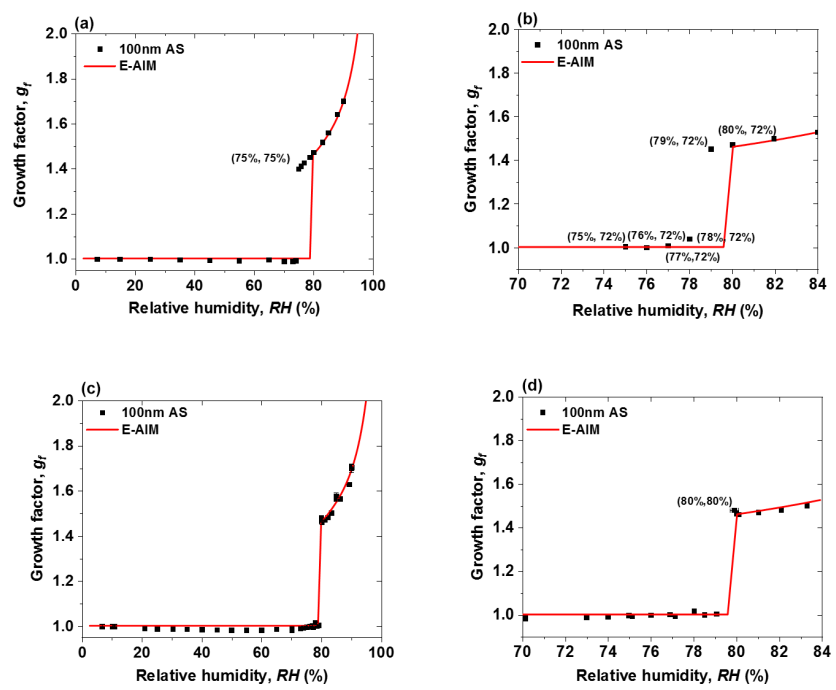

Figure 4. Mobility diameter hygroscopic growth factors $\left(g_{\mathrm{f}}\right)$ of $100 \mathrm{~nm}$ ammonium sulfate (AS) nanoparticles at $298 \mathrm{~K}$ measured in deliquescence mode. In comparison, the E-AIM model predicted growth factors of ammonium sulfate nanoparticles at $100 \mathrm{~nm}$. (a) $\mathrm{RH}_{\mathrm{e}}=\mathrm{RH}_{\mathrm{a}}(75 \%, 75 \%)$ represents the $\mathrm{RH}_{\mathrm{e}}$ and $\mathrm{RH}_{\mathrm{a}}$; (b) $\mathrm{RH}_{\mathrm{e}} \geq \mathrm{RH}_{\mathrm{a}}+3 \%(75 \%, 72 \%)$ represents the $\mathrm{RH}_{\mathrm{e}}$ and $\mathrm{RH}_{\mathrm{a}}$; and (c) $\mathrm{RH}_{\mathrm{s}}=\mathrm{RH}_{\mathrm{a}}$. (d) The enlarged view of the $\mathrm{RH}$ range of $70 \%$ to $84 \%$ in Fig. $4 \mathrm{c}$. The $(80 \%, 80 \%)$ points represent the $\mathrm{RH}_{\mathrm{s}}$ and $\mathrm{RH}_{\mathrm{a}} \cdot \mathrm{RH}_{\mathrm{s}}$ and $\mathrm{RH}_{\mathrm{e}}$ are the $\mathrm{RH}$ of sheath flow in the inlet of nanoDMA2 and in the excess air line, respectively. $\mathrm{RH}_{\mathrm{a}}$ is the $\mathrm{RH}$ of aerosol flow in the inlet of nano-DMA2.

that the RH upstream of nano-DMA2 has already reached the deliquescence $\mathrm{RH}$ of ammonium sulfate nanoparticles. When these aerosol nanoparticles move downstream of the nano-DMA2, the RH decreases back to $75 \%$, which dehydrates the deliquesced ammonium sulfate nanoparticles. To avoid the predeliquescence, Hämeri et al. (2001) have suggested setting $\mathrm{RH}_{\mathrm{a}}$ to be $3 \%-5 \%$ lower than $\mathrm{RH}_{\mathrm{e}}$. In the second test, we configured and regulated the system following this suggestion, i.e., $\mathrm{RH}_{\mathrm{e}} \geq \mathrm{RH}_{\mathrm{a}}+3 \%$. In this case, the ammonium sulfate nanoparticles still deliquesce at $79 \% \mathrm{RH}$ (Fig. 4b), even if $\mathrm{RH}_{\mathrm{a}}$ is $6 \%$ lower than $\mathrm{RH}_{\mathrm{e}}$.

Previous studies (Biskos et al., 2006b; Bezantakos et al., 2016) have shown that RH nonuniformities within the nanoDMA2 can result in inaccurate measurements of the phase transition and hygroscopic growth of aerosol nanoparticles. One reason for RH nonuniformities within nano-DMA2 is that the sheath flow RH is different from the aerosol flow RH at the inlet of the DMA (Hämeri et al., 2000, 2001). Another important reason is the existence of the temperature gradient within nano-DMA2 (Bezantakos et al., 2016). Hence, in the third test, we moved the RH sensor from the excess flow downstream of the nano-DMA2 to the sheath flow upstream of the nano-DMA2 and then regulated $\mathrm{RH}$ of sheath flow $\left(\mathrm{RH}_{\mathrm{s}}\right)$ to be the same as $\mathrm{RH}_{\mathrm{a}}$ (shown in Fig. 1); i.e., $\mathrm{RH}_{\mathrm{s}}=\mathrm{RH}_{\mathrm{a}}$ as done by Kreidenweis et al. (2005), Biskos et al. (2006a, b), and Massling et al. (2011). Note that, to mini- 


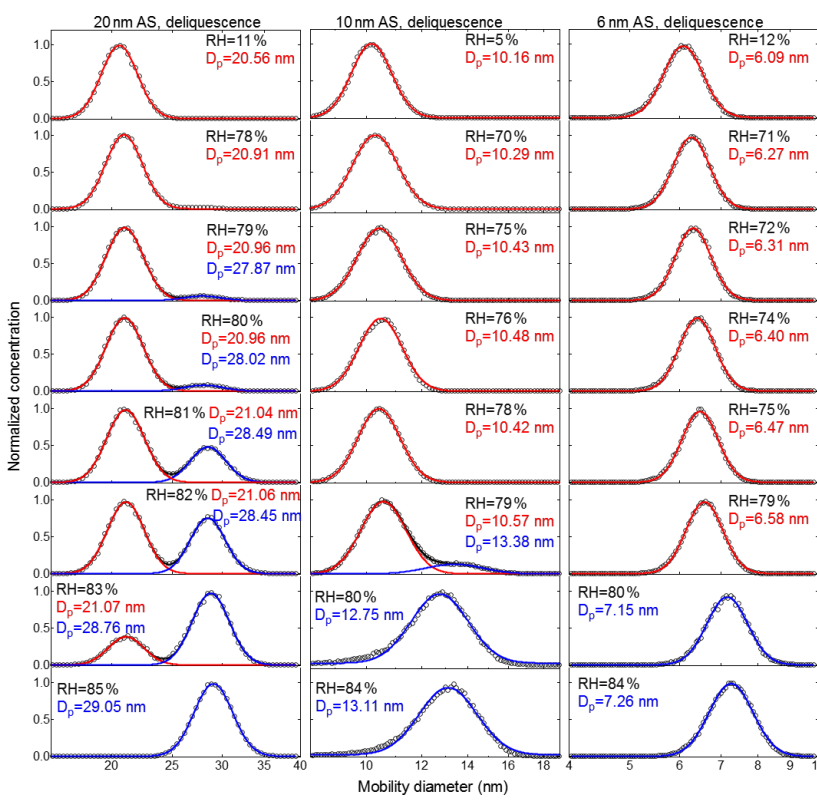

Figure 5. Deliquescence-mode measurements of ammonium sulfate (AS) aerosol nanoparticles with a dry mobility diameter from 20 $6 \mathrm{~nm}$. The measured (black circles) and fitted (solid lines) normalized size distribution are shown for increasing RH. The red and blue lines represent the aerosol nanoparticles in the solid and liquid state, respectively. The RH history in each measurement is $5 \% \rightarrow X \%$, where $X$ is the $\mathrm{RH}$ value given in each panel.

mize the temperature gradient within the nano-DMA2 in our system so that nanoparticles can undergo almost the same RH conditions, the nano-DMA2 with its sheath flow humidification system has been placed in a well-insulated, airconditioned chamber. The air temperature inside the chamber can be maintained at an almost constant level $(292.15 \pm$ $0.1 \mathrm{~K}$ ). In addition, a heat exchanger was installed downstream of the recirculation blower to minimize the temperature perturbation in the sheath flow by the heat generated in the RB. Unlike previously reported by Bezantakos et al. (2016), who said that the RH at the outlet was higher than at the inlet of the sheath air, we monitored the sheath flow temperature at the inlet of nano-DMA2 so that it was slightly lower (less than $\sim 0.2 \mathrm{~K}$ ) than that at the outlet (i.e., the $\mathrm{RH}_{\mathrm{S}}$ at the inlet of nano-DMA2 is slightly higher $(\sim 1 \%)$ than the RH of the excess air at the outlet), while the temperature of the sheath flow was equal to that of the aerosol flow at the inlet of nano-DMA2 during the measurements. A small temperature difference in nano-DMA2 is more likely due to the heat transfer between the inner electrode and air which flows around it by convection and conduction (Bezantakos et al., 2016). The plausible reason for this could be that when charged nanoparticles (similar to the electric current) hit the inner electrode, the inner electrode has some resistive heating from the electric current that flows. Such a temperature difference and gradient within DMA was ob- served in previous studies (Biskos et al., 2006a; Villani et al., 2008; Duplissy et al., 2009; Bezantakos et al., 2016; Giamarelou et al., 2018). For example, a $\pm 0.5^{\circ} \mathrm{C}$ temperature difference within DMA was observed by Giamarelou et al. (2018) during the measurements. Except for the possibly slightly higher temperature of the inner electrode than the surrounding air, the temperature gradient in DMA2 may also be caused by environmental disturbances or temperature differences between other parts of DMA and between sheath flow and aerosol flow. In this study, we calculate the change in heat $(Q)$ of a nano-DMA2 system at a constant pressure, which is estimated to be $\sim 0.08 \mathrm{~W}\left(Q=\right.$ mdTC $\left._{\mathrm{p}, \mathrm{k}}\right)$ by considering the density and heating capacity of air and the aerosol and sheath air flow rate $\left(\rho=1.2041 \mathrm{~kg} \mathrm{~m}^{-3} ; C_{\mathrm{p}}=\right.$ $1.859 \mathrm{~kJ} \mathrm{~kg}^{-1}{ }^{\circ} \mathrm{C}$; Atkins et al., 2006). Although this temperature perturbation (less than $\sim 0.2 \mathrm{~K}$ between the sheath flow at the inlet and the excess flow at the outlet of the nanoDMA2) is larger than the ideal condition of less than $0.1 \mathrm{~K}$ that Duplissy et al. (2009) and Wiedensohler et al. (2012) suggested, our experimental results show that a prompt phase transition can still be achieved. In this case, the measured DRH of ammonium sulfate nanoparticles is almost at $80 \%$ (Fig. 4c and d).

\subsubsection{Prompt phase transition of ammonium sulfate}

Figures 5 and 6 show the normalized particle number size distributions measured by the nano-DMA2 in the respective deliquescence and efflorescence measurement modes for ammonium sulfate nanoparticles with dry mobility diameters of 20, 10, and $6 \mathrm{~nm}$ (see Fig. S4 for $100 \mathrm{~nm}$; see Fig. S5 for $60 \mathrm{~nm}$; see Fig. S6 for $8 \mathrm{~nm}$ ). In the deliquescence measurement mode (Figs. 5, S4a, and S5a), we observed a similar double-mode phenomenon to that reported by Mikhailov et al. (2004) and Biskos et al. (2006a, b). For example, at $20 \mathrm{~nm}$ there are two distinct intersecting modes of particle size distributions determined by the nano-DMA2 in the RH range from $79 \%$ to $83 \% \mathrm{RH}$ (around the DRH of ammonium sulfate). Biskos et al. (2006a, b) attributed these two modes to the coexistence of solid and liquid phase nanoparticles at RH close to the DRH of ammonium sulfate. This is due to the slight inhomogeneity of RH in the second nanoDMA, i.e., some nanoparticles have already undergone deliquescence (liquid state) and some have not (solid). This is evident through a double-mode log-normal fitting (red and blue modes in Fig. 5). Until RH $\sim 82 \%$, the peak diameter of the red mode at $82 \% \mathrm{RH}$ is similar to that at $11 \% \mathrm{RH}$, indicating that these nanoparticles are still in a solid state. At $82 \% \mathrm{RH}$, a population of ammonium sulfate nanoparticles starts to deliquesce and exists in a distinct mode with a significantly larger peak diameter (blue mode), although the majority of the nanoparticles remain solid (red mode). As $\mathrm{RH}$ further increases, the peak diameter of the normalized number size distribution of the blue mode increases, indicating the continuous growth of the nanoparticles after deliques- 


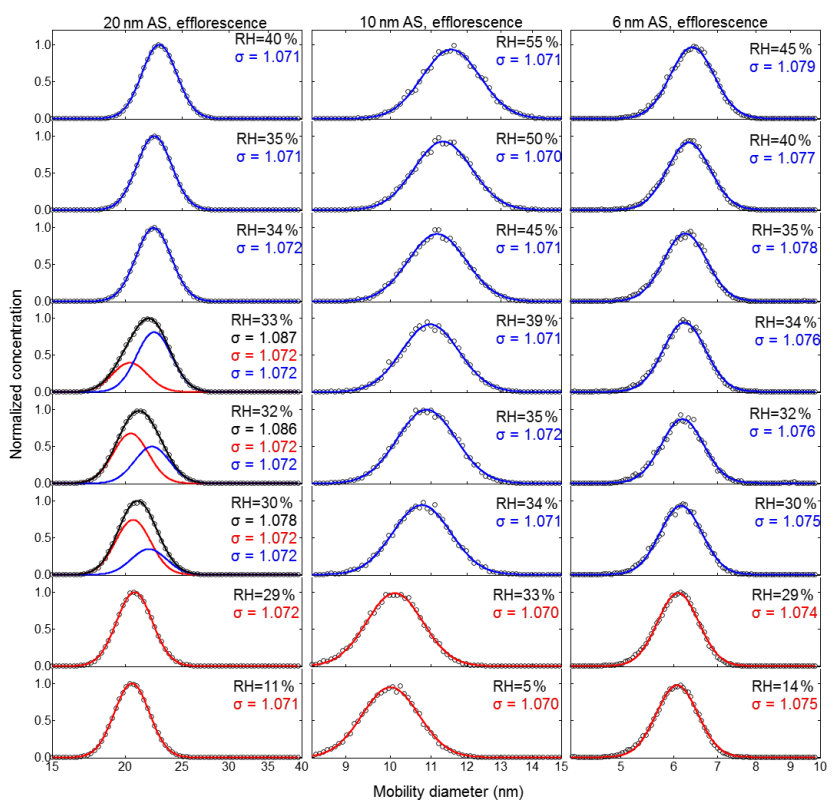

Figure 6. Efflorescence-mode measurements of ammonium sulfate (AS) aerosol nanoparticles with a dry mobility diameter from 20 $6 \mathrm{~nm}$. The measured (black circles) and fitted (solid lines) normalized size distribution are shown for increasing RH. The red and blue lines represent the aerosol nanoparticles in the solid and liquid state, respectively. The RH history in each measurement is $5 \% \rightarrow 97 \% \rightarrow X \%$, where $X$ is the $\mathrm{RH}$ value given in each panel.

cence. However, in our case, the double-mode phenomenon was not observed for 8 and $6 \mathrm{~nm}$ ammonium sulfate nanoparticles (Figs. 5 and S6a). To have a better estimation of DRH when the double modes occurred, the peak diameter of the mode with the larger number of nanoparticles was chosen for growth factor calculation (Biskos et al., 2006a, b). For example, for $20 \mathrm{~nm}$ ammonium sulfate nanoparticles, the peak diameters of the normalized number size distribution of the red and blue modes are used to calculate the growth factor at RH between $79 \%$ to $83 \%$, respectively.

For the efflorescence measurement mode, we adopted the approach of Biskos et al. (2006b) and used the geometric standard deviation of the number size distribution (i.e., sigma $-\sigma)$ to quantify the diversity in the sizes of the nanoparticles. As shown in Figs. 6, S4b, S5b, and S6b, a broadening of the normalized number size distributions measured with nano-DMA2 was only observed for $20 \mathrm{~nm}$ ammonium sulfate nanoparticles in the $\mathrm{RH}$ range from $33 \%$ to $30 \%$. There, at RH higher than $33 \%$ or lower than $30 \%, \sigma$ stays stable at 1.072. However, clear increases in $\sigma(1.078-1.087)$ were observed for RH between $33 \%$ and $30 \%$. The normalized number size distributions in the RH range from $33 \%$ to $30 \%$ can be further resolved by double-mode fit with a fixed $\sigma$ of 1.072 (the red and the blue mode in Fig. 6 for $20 \mathrm{~nm}$ ). The ammonium sulfate nanoparticles in the red mode at RH between $33 \%$ and $30 \%$ are in the solid state because the peak diameter of red mode is similar to that at $11 \% \mathrm{RH}$. However, within this RH range, the peak diameter of the blue mode is significantly larger, indicating that these nanoparticles are still in the liquid state. Further decreasing RH (lower than $30 \%$ ) leads to only one mode being observed, and the peak diameter of the normalized number size distribution is almost unchanged as RH decreases (red mode in Fig. 6 for $20 \mathrm{~nm}$ ), which means that the nanoparticles have all been in the solid state. Similar to the deliquescence measurement shown above and in Fig. 5, the coexistence of solid and aqueous phase nanoparticles at RH $30 \%-33 \%$ is also very likely to stem from the slightly heterogeneous RH in nano-DMA2 (Biskos et al., 2006b). To have a better estimation of ERH when the broadening phenomenon exists, the peak diameter of the mode with the larger number of nanoparticles was used for the growth factor calculation. After such data processing in both the deliquescence and efflorescence modes, we obtained prompt deliquescence and efflorescence of 6 to $100 \mathrm{~nm}$ ammonium sulfate nanoparticles (more details in Sect. 3.1.4).

\subsubsection{Size-dependent hygroscopicity of ammonium sulfate nanoparticles}

Figure 7 shows the humidogram of ammonium sulfate nanoparticles measured by our nano-HTDMA system in the size (dry diameter) range of 6-100 $\mathrm{nm}$. The detailed comparison between our results and those of Biskos et al. (2006b) during both deliquescence and efflorescence measurements is presented in Fig. 8a and b (also Fig. S7). In general, our results are in good agreement with the measurement results of Biskos et al. (2006b) and the theoretical prediction by Cheng et al. (2015). First, there is a strong size dependence in the hygroscopic growth factor of ammonium sulfate nanoparticles, and smaller ammonium sulfate nanoparticles exhibit a lower growth factor at a certain RH. For example, the difference in the growth factor between 6 and $100 \mathrm{~nm}$ nanoparticles is up to 0.28 at $80 \%$ RH (Fig. S8a). Second, there is, however, no significant size dependence in both DRH and ERH (Fig. S8b). For nanoparticles of different sizes (6$100 \mathrm{~nm}$ ), the DRH and ERH of ammonium sulfate varies slightly from $\sim 80 \%$ to $83 \%$ and $\sim 30 \%$ to $34 \%$, respectively. This variation in the DRH and ERH with respect to the size is much smaller for ammonium sulfate nanoparticles than for sodium chloride (Biskos et al., 2006a, c).

Although our results in general agree well with Biskos et al. (2006b), the growth factors of 10,8 , and $6 \mathrm{~nm}$ ammonium sulfate nanoparticles that we measured at high RH (i.e., $>\sim 70 \%)$ are slightly lower $(\sim 0.02$ in growth factor) than those in Biskos et al. (2006b) in both deliquescence and efflorescence processes (Figs. 8b and S7). We calculated the uncertainties in the growth factor of $10 \mathrm{~nm}$ ammonium sulfate from $80 \%$ to $90 \% \mathrm{RH}$ for our system and the Biskos et al. (2006b) system with the follow- 


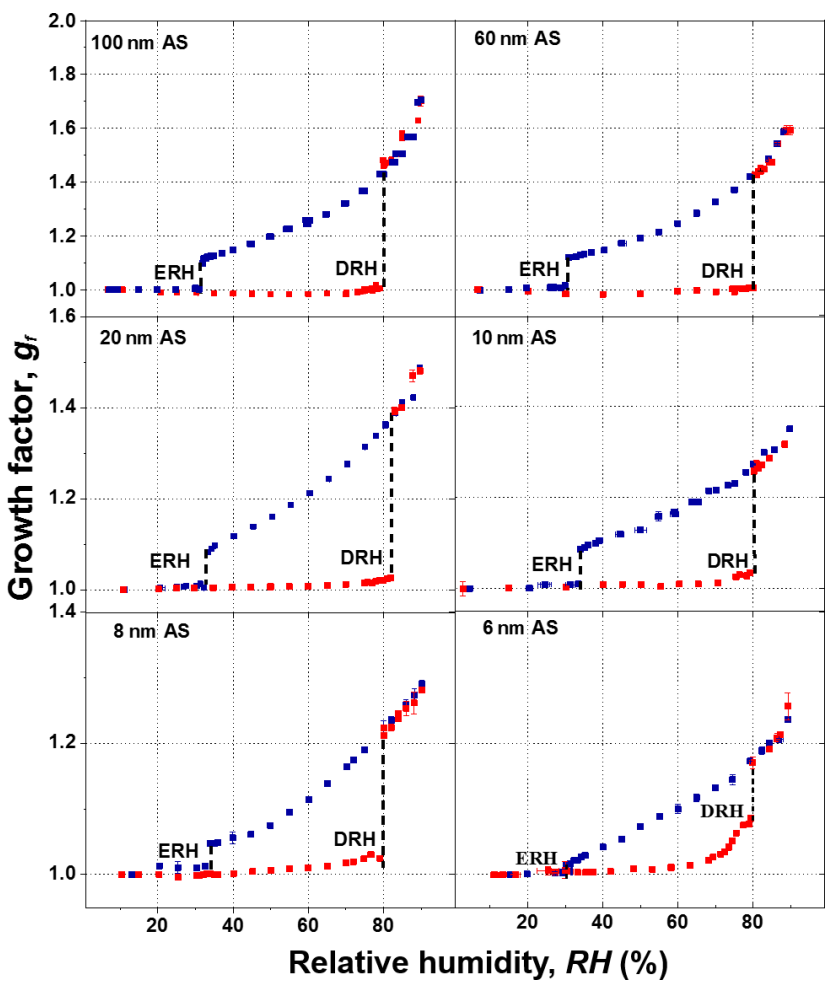

Figure 7. Mobility diameter hygroscopic growth factors $\left(g_{\mathrm{f}}\right)$ of ammonium sulfate (AS) aerosol nanoparticles with a dry mobility diameter from 6 to $100 \mathrm{~nm}$ in the deliquescence mode (red square and error bar) and the efflorescence mode (royal blue square and error bar). Deliquescence and efflorescence relative humidity (DRH and ERH; black dashed line) of ammonium sulfate (AS) nanoparticles with dry mobility diameter from 6 to $100 \mathrm{~nm}$.

ing: $\sqrt{\left(\left(g_{\mathrm{f}} \frac{\sqrt{2} \varepsilon_{\mathrm{D}_{\mathrm{p}}}}{D_{\mathrm{p}}}\right)^{2}+\left(\varepsilon_{\mathrm{RH}} \frac{d g_{\mathrm{f}}}{d \mathrm{RH}}\right)^{2},\right)}$ (Mochida and Kawamura, 200). Here, $\varepsilon_{\mathrm{Dp}}, \varepsilon_{\mathrm{RH}}$, and $g_{\mathrm{f}}$ are the uncertainty of the particle mobility diameter, the uncertainty of relative humidity, and the growth factor with respect to $\mathrm{RH}$, respectively. The average sizing offsets of our system, and the system of Biskos et al. (2006b) for $10 \mathrm{~nm}$ ammonium sulfate, are taken here as $\frac{\varepsilon_{\mathrm{Dp}}}{D_{\mathrm{p}}}$ (see Table 1). As shown in the inset of Fig. $8 \mathrm{~b}$, the discrepancies between the two systems are still within the measurement uncertainty.

In addition, compared to Biskos et al. (2006b), our results show a similar restructuring in the deliquescence mode at $\mathrm{RH}$ between about $20 \%$ and $75 \%$ for 100 and $60 \mathrm{~nm}$ ammonium sulfate nanoparticles (Fig. 8c). However, different to Biskos et al. (2006b), we do not find restructuring for smaller ammonium sulfate nanoparticles $(20,10,8$, and $6 \mathrm{~nm})$ at RH below the deliquescence point (Fig. 8c and d). There seems to be continuous water adsorption, and the adsorbed water layers (Romakkaniemi et al., 2001) become significantly thicker when $\mathrm{RH}$ is closer to the DRH (i.e, $\mathrm{RH}>70 \%$ ). For example, a slight increase in the hygroscopic growth factor of
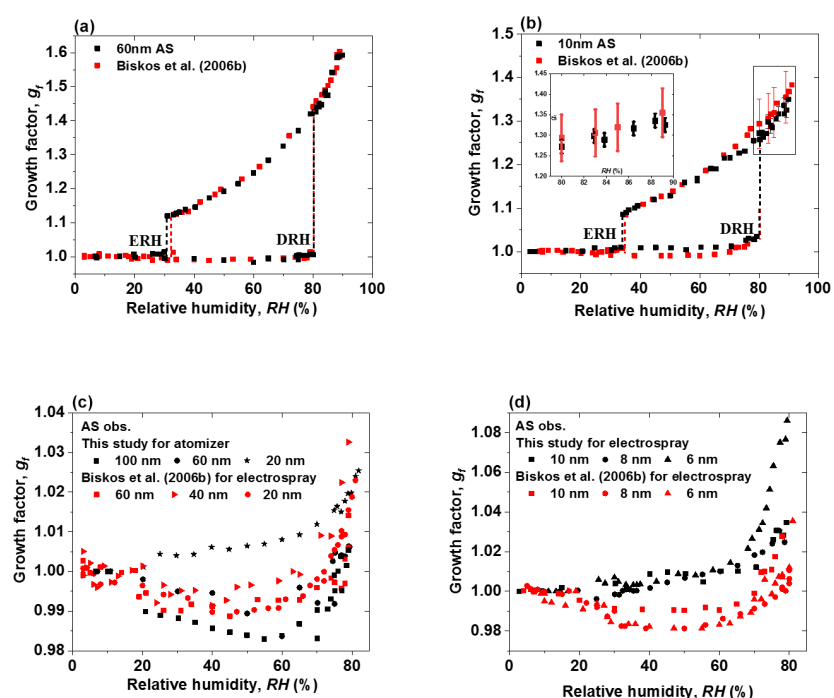

Figure 8. (a-b) Mobility diameter hygroscopic growth factors $\left(g_{\mathrm{f}}\right.$; black squares), deliquescence and efflorescence relative humidity (DRH and ERH; black dashed lines) of ammonium sulfate (AS) nanoparticles with a dry diameter of 60 and $10 \mathrm{~nm}$, respectively. Red squares and red dashed lines show the respective results from Biskos et al. (2006b), respectively. Black and red uncertainties of growth factors at certain $\mathrm{RH}$ are calculated by the following: $\sqrt{\left(\left(g_{\mathrm{f}} \frac{\sqrt{2} \varepsilon_{\mathrm{Dp}}}{D_{\mathrm{p}}}\right)^{2}+\left(\varepsilon_{\mathrm{RH}} \frac{d \mathrm{~g}_{\mathrm{f}}}{d \mathrm{RH}}\right)^{2}\right)}$, where $\varepsilon_{\mathrm{Dp}}, \varepsilon_{\mathrm{RH}}$, and $g_{\mathrm{f}}$ are the uncertainty of particle mobility diameter, the uncertainty of relative humidity, and the growth factor with respect to $\mathrm{RH}$, respectively (Mochida and Kawamura 2004). (c-d) Comparison of growth factors of ammonium sulfate (AS) nanoparticles with a dry diameter range from 6 to $100 \mathrm{~nm}$, with Biskos et al. (2006b) prior to deliquescence of ammonium sulfate nanoparticles.

$6 \mathrm{~nm}$ ammonium sulfate nanoparticles is observed in the $\mathrm{RH}$ range from $65 \%$ to $79 \% \mathrm{RH}$ before deliquescence. This is attributed to water adsorption on the surfaces of these nanoparticles. It seems that smaller nanoparticles have a stronger tendency to adsorb water when approaching the DRH than the larger ones. A similar phenomenon was also observed by Hämeri et al. (2000, 2001), Romakkaniemi et al. (2001), Biskos et al. (2006a, b, c), and Giamarelou et al. (2018). The reason for such enhanced adsorption at smaller sizes still needs to be investigated. Note that the ammonium sulfate hygroscopic data from Biskos et al. (2006b) shown here are all generated by an electrospray, but in our experiments, only the ammonium sulfate nanoparticles with diameters smaller than $20 \mathrm{~nm}$ (i.e., 10,8 , and $6 \mathrm{~nm}$ ) were generated by an electrospray, while the larger nanoparticles (i.e., 20, 60, and $100 \mathrm{~nm}$ ) were generated by an atomizer. Different from the generation conditions for 6-10 $\mathrm{nm}$ ammonium sulfate nanoparticles in Biskos et al. (2006b), in our study, in order to minimize the multiple charged nanoparticles, three different concentrations were used so that the size selected by the nano-DMA1 (i.e., 6,8 , and $10 \mathrm{~nm}$ ) was always slightly larger than peak 
of the number size distribution of the nanoparticles generated by the electrospray. This also helps us to have as many as nanoparticles as possible to compensate for the strong nanoparticle losses in the nano-HTDMA system. In addition, we used both an electrospray and an atomizer to generate $20 \mathrm{~nm}$ ammonium sulfate, and we compared their hygroscopic growth factors prior to deliquescence. Figure S12a shows a $\sim 0.1$ higher growth factor of $20 \mathrm{~nm}$ ammonium sulfate generated by the electrospray than when using the atomizer in the RH range from $55 \%$ to $82 \%$, which is similar to the difference in the hygroscopic growth factor of $20 \mathrm{~nm}$ $\mathrm{NaCl}$ aerosol nanoparticles when using the different generation methods, shown in Fig. S12b, in Biskos et al. (2006a). Besides different generation conditions, the morphology of the dried ammonium sulfate particles may also differ slightly between our study and Biskos et al. (2006b) because of the different drying rate, as the drying flow rates and $\mathrm{RH}$ of the dried ammonium sulfate in the two HTDMA systems are different too. This means the different generation methods and drying conditions may influence the surface structure of the nanoparticles and, thus, their interaction with the adsorbed water layers (Iskandar et al., 2003; Wang et al., 2019).

\subsection{Size-dependent hygroscopicity of sodium sulfate nanoparticles}

As it is a common constituent of atmospheric aerosol particles (Tang and Munkelwitz, 1993, 1994; Tang, 1996; Tang et al., 1995), the hygroscopicity of sodium sulfate with diameters above $20 \mathrm{~nm}$ particles has been investigated by a few groups (Tang et al., 1995; Xu and Schweiger, 1999; Hu et al., 2010). However, its hygroscopic behavior in the sub- $10 \mathrm{~nm}$ size range has not been investigated yet. In this study, we applied our nano-HTDMA system to measure the hygroscopic growth factors, DRH, and ERH of sodium sulfate nanoparticles with a dry size from $20 \mathrm{~nm}$ down to $6 \mathrm{~nm}$.

Figure 9 shows the measured size-resolved hygroscopic growth factors of sodium sulfate nanoparticles. Different from the observations by Tang et al. (1995) using an electrodynamic balance (EDB), we observed a prompt deliquescence and efflorescence for both 20 and $6 \mathrm{~nm}$ sodium sulfate nanoparticles. Two intersecting modes in the measured number size distribution of the humidified sodium sulfate nanoparticles are observed at RH close to the DRH (Figs. S9 and S10) and at ERH, suggesting an external mixture of aqueous and solid nanoparticles. As shown in Sect. 3.1.3, a similar phenomenon is also observed for ammonium sulfate, which could be attributed to the slight RH heterogeneities in nano-DMA2; this makes only part of the nanoparticles deliquesce at RH close to the DRH, while the others remain in the solid state.

Together with the hygroscopic growth of $14-16 \mu \mathrm{m}$ and $200-20 \mathrm{~nm}$ sodium sulfate measured previously by Tang et al. (1995) and Hu et al. (2010), we show a strong size dependence in hygroscopic growth factors of sodium sulfate

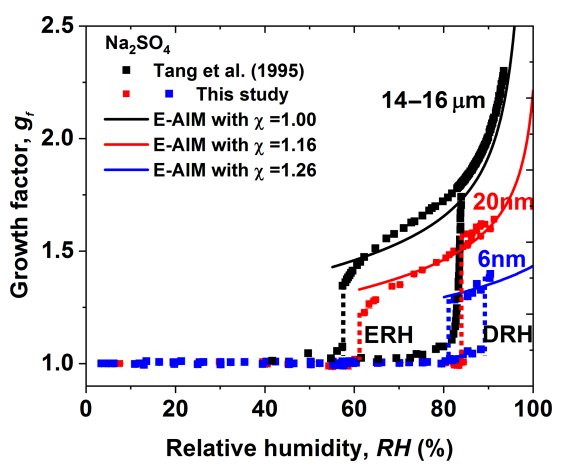

Figure 9. Mobility diameter hygroscopic growth factors $\left(g_{\mathrm{f}}\right)$ and deliquescence and efflorescence relative humidity (DRH and ERH; red and blue dashed lines) of sodium sulfate nanoparticles with a dry diameter of $20 \mathrm{~nm}$, (red squares) and $6 \mathrm{~nm}$, (blue squares), respectively. Black squares and black dashed lines show the respective results from Tang et al. (1995) with electrodynamic balance (EDB), respectively. In this study, the black, red, and blue curves show the E-AIM predictions, including the Kelvin effect and shape factors $(\chi)$.

nanoparticles (Fig. S11d). For example, at $\mathrm{RH}=84 \%$, the hygroscopic growth factor of $6 \mathrm{~nm}$ sodium sulfate is only $\sim 1.3$ (in efflorescence mode), while the respective growth factors are about 1.5 and 1.8 for $20 \mathrm{~nm}$ and $14-16 \mu \mathrm{m}$ particles. As shown in Fig. 9, E-AIM already agrees well with the hygroscopic growth of micrometer particles $(14-16 \mu \mathrm{m})$ without shape correction (DeCarlo et al., 2004), i.e., shape factor $(\chi)$ of 1.0. However, to explain observation, a shape factor of $\sim 1.16$ and 1.26 would be needed for 20 and $6 \mathrm{~nm}$ sodium sulfate nanoparticles, respectively.

There is no significant change in DRH between 14 and $16 \mu \mathrm{m}(\sim 84 \%)$ and $20 \mathrm{~nm}(\sim 84 \%)$ sodium sulfate particles (Fig. 9). This is consistent with $\mathrm{Hu}$ et al. (2010) where no change in DRH, from $200 \mathrm{~nm}$ down to $20 \mathrm{~nm}(\sim 82 \%$; see Table 1 from Hu et al., 2010), was observed. However, a significant increase in DRH occurred when further decreasing particle diameters to $6 \mathrm{~nm}(\mathrm{DRH}=\sim 90 \%)$. The size dependence of ERH is stronger than that of DRH, as there is already a clear increase in ERH from micrometer 14 to $16 \mu \mathrm{m}$ $(\sim 57 \%)$ to $20 \mathrm{~nm}(\sim 62 \%)$ sodium sulfate particles. When further reducing the particle diameters to $6 \mathrm{~nm}$, an almost $6 \%$ increase in DRH can be found, compared to the micrometer $14-16 \mu \mathrm{m}$ particles (i.e., ERH increases from $57 \%$ to $82 \%$, respectively). Different from ammonium sulfate, for which DRH and ERH show no significant size dependence, there is a strong size dependence in the DRH and ERH of sodium sulfate according to our observations down to $6 \mathrm{~nm}$. The difference in the size dependence of DRH and ERH between sodium chloride and ammonium sulfate has been theoretically studied and explained by Cheng et al. (2015). The main reason is the different concentration dependence of the solute activities and the different solute-liquid surface tension (e.g., the same change in solute molality leads to a larger 
change in the solute activity of sodium chloride than that of ammonium sulfate). The phase transition concentration (deliquescence and crystallization concentration) of ammonium sulfate is thus more sensitive to the size change compared to that of sodium chloride, leading to the almost unchanged DRH and ERH of ammonium sulfate nanoparticles (Cheng et al., 2015). For the size dependence of the phase transition of sodium sulfate, the strong size effect on DRH and ERH is similar to that of sodium chloride but different to that of ammonium sulfate in the size range from 6 to $20 \mathrm{~nm}$, suggesting that the nonideality of the solution property is close to that of sodium chloride but weaker than that of ammonium sulfate. As different hydrates of sodium sulfate may exist during the deliquescence and efflorescence processes ( $\mathrm{Xu}$ and Schweiger, 1999), explaining the underlying mechanism of the size-dependent hygroscopicity of sodium sulfate particles can be challenging.

\section{Summary and conclusion}

In this study, we presented our newly designed and selfassembled nano-HTDMA for measuring the hygroscopicity of nanoparticles in the sub-10 nm diameter size range. We also introduced comprehensive methods for system calibration and reported on the performance of the system, focusing on sizing accuracy and preventing predeliquescence in the deliquescence measurement mode. By comparing our findings with previous studies on ammonium sulfate nanoparticles (Biskos et al., 2006b), we show that our system is capable of providing high-quality data of the hygroscopic behavior of sub-10 nm nanoparticles. We then extended our measurements to sodium sulfate nanoparticles, for which sizedependent deliquescence and efflorescence have been clearly observed for nanoparticles down to $6 \mathrm{~nm}$ in size and which demonstrate similar behavior to sodium chloride.

As we know, atmospheric aerosol particles consist of not only inorganic components but also a vast number of other organic components existing in the atmosphere. However, their physicochemical properties are still not fully understood, especially when it comes to the nanoscale and supersaturated concentration range. The nano-HTDMA system can be directly applicable for exploring the size dependence of aerosol nanoparticles. By combining the multisize measurements of hygroscopicity and the differential Köhler analyses (DKA; Cheng et al., 2015) in the nano size range, we will be able to characterize and parameterize the water activity and surface tension of different inorganic and organic systems. This will further help us to understand the formation and transformation of aerosol nanoparticles in the atmosphere and their interaction with water vapor.

Data availability. Readers who are interested in the data should contact Yafang Cheng (yafang.cheng@mpic.de).
Supplement. The supplement related to this article is available online at: https://doi.org/10.5194/amt-13-5551-2020-supplement.

Author contributions. YC and HS designed and led the study. NM, TT, and AW assembled the basic HTDMA system. YC, HS, and TL modified and advanced the basic system into the nano-HTDMA for the purpose of measuring the hygroscopic properties of aerosol nanoparticles in the sub-10 $\mathrm{nm}$ size range at the Max Planck Institute for Chemistry (MPIC). TL performed the experiments. JH, $\mathrm{NM}$, and XW supported the experiments. All coauthors discussed the results and commented on the paper. TL wrote the paper with input from all coauthors.

Competing interests. The authors declare that they have no conflict of interest.

Acknowledgements. This study was supported by the Max Planck Society (MPG) and Leibniz Society. Ting Lei acknowledges support from the China Scholarship Council (CSC). Yafang Cheng would like to acknowledge the Minerva Program of MPG.

Financial support. The article processing charges for this openaccess publication were covered by the Max Planck Society.

Review statement. This paper was edited by Charles Brock and reviewed by two anonymous referees.

\section{References}

Andreae, M. O., Afchine, A., Albrecht, R., Holanda, B. A., Artaxo, P., Barbosa, H. M. J., Borrmann, S., Cecchini, M. A., Costa, A., Dollner, M., Fütterer, D., Järvinen, E., Jurkat, T., Klimach, T., Konemann, T., Knote, C., Krämer, M., Krisna, T., Machado, L. A. T., Mertes, S., Minikin, A., Pöhlker, C., Pöhlker, M. L., Pöschl, U., Rosenfeld, D., Sauer, D., Schlager, H., Schnaiter, M., Schneider, J., Schulz, C., Spanu, A., Sperling, V. B., Voigt, C., Walser, A., Wang, J., Weinzierl, B., Wendisch, M., and Ziereis, H.: Aerosol characteristics and particle production in the upper troposphere over the Amazon Basin, Atmos. Chem. Phys., 18, 921-961, https://doi.org/10.5194/acp-18-921-2018, 2018.

Atkins, P., De Paula, J., and Walters, V.: Physical Chemistry, W. H. Freeman, Oxford University Press, Oxford, 2006.

Bezantakos, S., Huang, L., Barmpounis, K., Martin, S. T., and Biskos, G.: Relative humidity non-uniformities in hygroscopic tandem differential mobility analyzer measurements, J. Aerosol Sci., 101, 1-9, https://doi.org/10.1016/j.jaerosci.2016.07.004, 2016.

Birmili, W., Stratmann, F., Wiedensohler, A., Covert, D., M. Russell, L., and Berg, O.: Determination of differential mobility analyzer transfer functions using identical instruments in Series, Aerosol Sci. Technol., 27, 215-223, 1997. 
Birmili, W., Weinhold, K., Rasch, F., Sonntag, A., Sun, J., Merkel, M., Wiedensohler, A., Bastian, S., Schladitz, A., Löschau, G., Cyrys, J., Pitz, M., Gu, J., Kusch, T., Flentje, H., Quass, U., Kaminski, H., Kuhlbusch, T. A. J., Meinhardt, F., Schwerin, A., Bath, O., Ries, L., Gerwig, H., Wirtz, K., and Fiebig, M.: Longterm observations of tropospheric particle number size distributions and equivalent black carbon mass concentrations in the German Ultrafine Aerosol Network (GUAN), Earth Syst. Sci. Data, 8, 355-382, https://doi.org/10.5194/essd-8-355-2016, 2016.

Biskos, G., Malinowski, A., Russell, L. M., Buseck, P. R., and Martin, S. T.: Nanosize effect on the deliquescence and the efflorescence of sodium chloride particles, Aerosol Sci. Technol., 40, 97-106, 2006a.

Biskos, G., Paulsen, D., Russell, L. M., Buseck, P. R., and Martin, S. T.: Prompt deliquescence and efflorescence of aerosol nanoparticles, Atmos. Chem. Phys., 6, 4633-4642, https://doi.org/10.5194/acp-6-4633-2006, 2006b.

Biskos, G., Russell, L. M., Buseck, P. R., and Martin, S. T.: Nanosize effect on the hygroscopic growth factor of aerosol particles, Geophys. Res. Lett., 33, L07801, https://doi.org/10.1029/2005GL025199, 2006c.

Chan, M. N. and Chan, C. K.: Hygroscopic properties of two model humic-like substances and their mixtures with inorganics of atmospheric importance, Environ. Sci. Technol., 37, 5109-5115, 2003.

Chan, M. N. and Chan, C. K.: Mass transfer effects in hygroscopic measurements of aerosol particles, Atmos. Chem. Phys., 5, 2703-2712, https://doi.org/10.5194/acp-5-2703-2005, 2005.

Chan, M. N., Kreidenweis, S. M., and Chan, C. K.: Measurements of the hygroscopic and deliquescence properties of organic compounds of different solubilities in water and their relationship with cloud condensation nuclei activities, Environ. Sci. Technol., 42, 3602-3608, 2008.

Cheng, Y. F., Wiedensohler, A., Eichler, H., Heintzenberg, J., Tesche, M., Ansmann, A., Wendisch, M., Su, H., Althausen, D., Herrmann, H., Gnauk, T., Brüggemann, E., Hu, M., and Zhang, Y. H.: Relative humidity dependence of aerosol optical properties and direct radiative forcing in the surface boundary layer at Xinken in Pearl River Delta of China: An observation based numerical study, Atmos. Environ., 42, 6373-6397, 2008.

Cheng, Y. F., Berghof, M., Garland, R. M., Wiedensohler, A., Wehner, B., Muller, T., Su, H., Zhang, Y. H., Achtert, P., Nowak, A., Pöschl, U., Zhu, T., Hu, M., and Zeng, L. M.: Influence of soot mixing state on aerosol light absorption and single scattering albedo during air mass aging at a polluted regional site in northeastern China, J. Geophys. Res., 114, D00G10, https://doi.org/10.1029/2008JD010883, 2009.

Cheng, Y. F., Su, H., Koop, T., Mikhailov, E., and Pöschl, U.: Size dependence of phase transitions in aerosol nanoparticles, Nat. Commun., 6, 5923, https://doi.org/10.1038/ncomms6923, 2015.

Cheng, Y. F., Zheng, G. J., Wei, C., Mu, Q., Zheng, B., Wang, Z. B., Gao, M., Zhang, Q., He, K. B., Carmichael, G., Pöschl, U., and $\mathrm{Su}, \mathrm{H}$.: Reactive nitrogen chemistry in aerosol water as a source of sulfate during haze events in China, Sci. Adv., 2, e1601530, https://doi.org/10.1126/sciadv.1601530, 2016.

Clegg, S. L., Brimblecombe, P., and Wexler, A. S.: Thermodynamic model of the system $\mathrm{H}^{+}-\mathrm{NH}_{4}^{+}-\mathrm{SO}_{4}^{2-}-\mathrm{NO}^{3-}-\mathrm{H}_{2} \mathrm{O}$ at tropospheric temperatures, J. Phys. Chem. A, 102, 2137-2154, https://doi.org/10.1021/Jp973042r, 1998.
DeCarlo, P. F., Slowik, J. G., Worsnop, D. R., Davidovits, P., and Jimenez, J. L.: Particle morphology and density characterization by combined mobility and aerodynamic diameter measurements. Part 1: Theory, Aerosol Sci. Technol., 38, 1185-1205, 2004.

Dong, J. L., Xiao, H. S., Zhao, L. J., and Zhang, Y.-H.: Spatially resolved Raman investigation on phase separations of mixed $\mathrm{Na}_{2} \mathrm{SO}_{4} / \mathrm{MgSO}_{4}$ droplets, J. Raman Spectrosc., 40, 338-343, 2009.

Dunne, E. M., Gordon, H., Kürten, A., Almeida, J., Duplissy, J., Williamson, C., Ortega, I. K., Pringle, K. J., Adamov, A., Baltensperger, U., Barmet, P., Benduhn, F., Bianchi, F., Breitenlechner, M., Clarke, A., Curtius, J., Dommen, J., Donahue, N. M., Ehrhart, S., Flagan, R. C., Franchin, A., Guida, R., Hakala, J., Hansel, A., Heinritzi, M., Jokinen, T., Kangasluoma, J., Kirkby, J., Kulmala, M., Kupc, A., Lawler, M. J., Lehtipalo, K., Makhmutov, V., Mann, G., Mathot, S., Merikanto, J., Miettinen, P., Nenes, A., Onnela, A., Rap, A., Reddington, C. L. S., Riccobono, F., Richards, N. A. D., Rissanen, M. P., Rondo, L., Sarnela, N., Schobesberger, S., Sengupta, K., Simon, M., Sipilä, M., Smith, J. N., Stozkhov, Y., Tomé, A., Tröstl, J., Wagner, P. E., Wimmer, D., Winkler, P. M., Worsnop, D. R., and Carslaw, K. S.: Global atmospheric particle formation from CERN CLOUD measurements, Science, 354, 1119-1124, 2016.

Duplissy, J., Gysel, M., Sjogren, S., Meyer, N., Good, N., Kammermann, L., Michaud, V., Weigel, R., Martins dos Santos, S., Gruening, C., Villani, P., Laj, P., Sellegri, K., Metzger, A., McFiggans, G. B., Wehrle, G., Richter, R., Dommen, J., Ristovski, Z., Baltensperger, U., and Weingartner, E.: Intercomparison study of six HTDMAs: results and recommendations, Atmos. Meas. Tech., 2, 363-378, https://doi.org/10.5194/amt-2363-2009, 2009.

Ehn, M., Thornton, J. A., Kleist, E., Sipilä, M., Junninen, H., Pullinen, I., Springer, M., Rubach, F., Tillmann, R., Lee, B., LopezHilfiker, F., Andres, S., Acir, I.-H., Rissanen, M., Jokinen, T., Schobesberger, S., Kangasluoma, J., Kontkanen, J., Nieminen, T., Kurtén, T., Nielsen, L. B., Jørgensen, S., Kjaergaard, H. G., Canagaratna, M., Maso, M. D., Berndt, T., Petäjä, T., Wahner, A., Kerminen, V.-M., Kulmala, M., Worsnop, D. R., Wildt, J., and Mentel, T. F.: A large source of low-volatility secondary organic aerosol, Nature, 506, 476-479, 2014.

Eichler, H., Cheng, Y. F., Birmili, W., Nowak, A., Wiedensohler, A., Brüggemann, E., Gnauk, T., Herrmann, H., Althausen, D., Ansmann, A., Engelmann, R., Tesche, M., Wendisch, M., Zhang, Y. H., Hu, M., Liu, S., and Zeng, L. M.: Hygroscopic properties and extinction of aerosol particles at ambient relative humidity in South-Eastern China, Atmos. Environ., 42, 6321-6334, https://doi.org/10.1016/j.atmosenv.2008.05.007, 2008.

Estillore, A. D., Morris, H. S., Or, V. W., Lee, H. D., Alves, M. R., Marciano, M. A., Laskina, O., Qin, Z., Tivanski, A. V., and Grassian, V. H.: Linking hygroscopicity and the surface microstructure of model inorganic salts, simple and complex carbohydrates, and authentic sea spray aerosol particles, Phys. Chem. Chem. Phys., 19, 21101-21111, 2017.

Fan, J. W., Rosenfeld, D., Zhang, Y. W., Giangrande, S. E., Li, Z. Q., Machado, L. A. T., Martin, S. T., Yang, Y., Wang, J., Artaxo, P., Barbosa, H. M. J., Braga, R. C., Comstock, J. M., Feng, Z., Gao, W. H., Gomes, H. B., Mei, F., Pöhlker, C., Pöhlker, M. L., Pöschl, U., and de Souza, R. A. F.: Substantial convection and precipi- 
tation enhancements by ultrafine aerosol particles, Science, 359, 411-418, 2018.

Gao, Y. G, Chen, S. B., and Yu, L. E.: Efflorescence relative humidity for ammonium sulfate particles, J. Phys. Chem. A, 110, 7602-7608, https://doi.org/10.1021/jp057574g, 2006.

Giamarelou, M., Smith, M., Papapanagiotou, E., Martin, S. T., and Biskos, G.: Hygroscopic properties of potassium-halide nanoparticles, Aerosol Sci. Technol., 52, 536-545, 2018.

Hämeri, K., Laaksonen, A., Väkevä, M., and Suni, T.: Hygroscopic growth of ultrafine sodium chloride particles, J. Geophys. Res., 106, 20749-20757, 2001.

Hämeri, K., Väkevä, M., Hansson, H.-C., and Laaksonen, A.: Hygroscopic growth of ultrafine ammonium sulfate aerosol measured using an ultrafine tandem differential mobility analyzer, J. Geophys. Res., 105, 22231-22242, 2000.

Hennig, T., Massling, A., Brechtel, F. J., and Wiedensohler, A.: A tandem DMA for highly temperature-stabilized hygroscopic particle growth measurements between $90 \%$ and $98 \%$ relative humidity, J. Aerosol Sci., 36, 1210-1223, 2005.

Hong, J., Häkkinen, S. A. K., Paramonov, M., Äijälä, M., Hakala, J., Nieminen, T., Mikkilä, J., Prisle, N. L., Kulmala, M., Riipinen, I., Bilde, M., Kerminen, V.-M., and Petäjä, T.: Hygroscopicity, $\mathrm{CCN}$ and volatility properties of submicron atmospheric aerosol in a boreal forest environment during the summer of 2010, Atmos. Chem. Phys., 14, 4733-4748, https://doi.org/10.5194/acp14-4733-2014, 2014.

Hong, J., Kim, J., Nieminen, T., Duplissy, J., Ehn, M., Äijälä, M., Hao, L. Q., Nie, W., Sarnela, N., Prisle, N. L., Kulmala, M., Virtanen, A., Petäjä, T., and Kerminen, V.-M.: Relating the hygroscopic properties of submicron aerosol to both gas- and particle-phase chemical composition in a boreal forest environment, Atmos. Chem. Phys., 15, 11999-12009, https://doi.org/10.5194/acp-15-11999-2015, 2015.

Hu, D. W., Qiao, L. P., Chen, J.-M., Ye, X. N, Yang, X., Cheng, T. T., and Fang, W.: Hygroscopicity of inorganic aerosols: size and relative humidity effects on the growth factor, Aerosol Air Qual. Res., 10, 255-264, 2010.

Iskandar, F., Gradon, L., and Okuyama, K.: Control of the morphology of nanostructured particles prepared by the spray drying of a nanoparticle sol, J. Colloid Interface Sci., 265, 296-303, 2003.

Kerminen, V.-M.: The effects of particle chemical character and atmospheric processes on particle hygroscopic properties, J. Aerosol Sci., 28, 121-132, 1997.

Keskinen, H., Virtanen, A., Joutsensaari, J., Tsagkogeorgas, G., Duplissy, J., Schobesberger, S., Gysel, M., Riccobono, F., Slowik, J. G., Bianchi, F., Yli-Juuti, T., Lehtipalo, K., Rondo, L., Breitenlechner, M., Kupc, A., Almeida, J., Amorim, A., Dunne, E. M., Downard, A. J., Ehrhart, S., Franchin, A., Kajos, M. K., Kirkby, J., Kürten, A., Nieminen, T., Makhmutov, V., Mathot, S., Miettinen, P., Onnela, A., Petäjä, T., Praplan, A., Santos, F. D., Schallhart, S., Sipilä, M., Stozhkov, Y., Tomé, A., Vaattovaara, P., Wimmer, D., Prevot, A., Dommen, J., Donahue, N. M., Flagan, R. C., Weingartner, E., Viisanen, Y., Riipinen, I., Hansel, A., Curtius, J., Kulmala, M., Worsnop, D. R., Baltensperger, U., Wex, H., Stratmann, F., and Laaksonen, A.: Evolution of particle composition in CLOUD nucleation experiments, Atmos. Chem. Phys., 13, 5587-5600, https://doi.org/10.5194/acp-13-5587-2013, 2013.

Kim, J., Ahlm, L., Yli-Juuti, T., Lawler, M., Keskinen, H., Tröstl, J., Schobesberger, S., Duplissy, J., Amorim, A., Bianchi, F., Don- ahue, N. M., Flagan, R. C., Hakala, J., Heinritzi, M., Jokinen, T., Kürten, A., Laaksonen, A., Lehtipalo, K., Miettinen, P., Petäjä, T., Rissanen, M. P., Rondo, L., Sengupta, K., Simon, M., Tomé, A., Williamson, C., Wimmer, D., Winkler, P. M., Ehrhart, S., Ye, P., Kirkby, J., Curtius, J., Baltensperger, U., Kulmala, M., Lehtinen, K. E. J., Smith, J. N., Riipinen, I., and Virtanen, A.: Hygroscopicity of nanoparticles produced from homogeneous nucleation in the CLOUD experiments, Atmos. Chem. Phys., 16, 293-304, https://doi.org/10.5194/acp-16-293-2016, 2016.

Kinney, P. D., Pui, D. Y. H., Mullholland, G. W., and Bryner, N. P.: Use of the electrostatic classification method to size $0.1 \mu \mathrm{m} \mathrm{SRM}$ particles - a feasibility Study. J. Res. Natl. Stand. Technol., 96, 147-176, 1991.

Kirkby, J., Curtius, J., Almeida, J., Dunne, E., Duplissy, J., Ehrhart, S., Franchin, A., Gagné, S., Ickes, L., Kürten, A., Kupc, A., Metzger, A., Riccobono, F., Rondo, L., Schobesberger, S., Tsagkogeorgas, G., Wimmer, D., Amorim, A., Bianchi, F., Breitenlechner, M., David, A., Dommen, J., Downard, A., Ehn, M., Flagan, R. C., Haider, S., Hansel, A., Hauser, D., Jud, W., Junninen, H., Kreissl, F., Kvashin, A., Laaksonen, A., Lehtipalo, K., Lima, J., Lovejoy, E. R., Makhmutov, V., Mathot, S., Mikkilä, J., Minginette, P., Mogo, S., Nieminen, T., Onnela, A., Pereira, P., Petäjä, T., Schnitzhofer, R., Seinfeld, J. H., Sipilä, M., Stozhkov, Y., Stratmann, F., Tomé, A., Vanhanen, J., Viisanen, Y., Vrtala, A., Wagner, P. E., Walther, H., Weingartner, E., Wex, H., Winkler, P. M., Carslaw, K. S., Worsnop, D. R., Baltensperger, U., and Kulmala, M.: Role of sulphuric acid, ammonia and galactic cosmic rays in atmospheric aerosol nucleation, Nature, 476, 429-433, 2011.

Knutson, E. O. and Whitby, K. T.: Aerosol classification by electric mobility: apparatus, theory, and applications, J. Aerosol Sci., 6, 443-451, 1975.

Köhler, H.: The nucleus in and the growth of hygroscopic droplets, Trans. Faraday Soc., 32, 1152-1161, 1936.

Kreidenweis, S. M., Koehler, K., DeMott, P. J., Prenni, A. J., Carrico, C., and Ervens, B.: Water activity and activation diameters from hygroscopicity data - Part I: Theory and application to inorganic salts, Atmos. Chem. Phys., 5, 1357-1370, https://doi.org/10.5194/acp-5-1357-2005, 2005.

Lei, T., Zuend, A., Wang, W. G., Zhang, Y. H., and Ge, M. F.: Hygroscopicity of organic compounds from biomass burning and their influence on the water uptake of mixed organic ammonium sulfate aerosols, Atmos. Chem. Phys., 14, 11165-11183, https://doi.org/10.5194/acp-14-11165-2014, 2014.

Lei, T., Zuend, A., Cheng, Y., Su, H., Wang, W., and Ge, M.: Hygroscopicity of organic surrogate compounds from biomass burning and their effect on the efflorescence of ammonium sulfate in mixed aerosol particles, Atmos. Chem. Phys., 18, 1045-1064, https://doi.org/10.5194/acp-18-1045-2018, 2018.

Lihavainen, H., Kerminen, V.-M., Komppula, M., Hatakka, J., Aaltonen, V., Kulmala, M., and Viisanen, Y.: Production of "potential" cloud condensation nuclei associated with atmospheric newparticle formation in northern Finland, J. Geophys. Res., 108, 4782, https://doi.org/10.1029/2003JD003887, 2003.

Massling, A., Niedermeier, N., Hennig, T., Fors, E. O., Swietlicki, E., Ehn, M., Hämeri, K., Villani, P., Laj, P., Good, N., McFiggans, G., and Wiedensohler, A.: Results and recommendations from an intercomparison of six Hygroscopicity-TDMA systems, Atmos. Meas. Tech., 4, 485-497, https://doi.org/10.5194/amt-4485-2011, 2011. 
Mikhailov, E. F. and Vlasenko, S. S.: High-humidity tandem differential mobility analyzer for accurate determination of aerosol hygroscopic growth, microstructure, and activity coefficients over a wide range of relative humidity, Atmos. Meas. Tech., 13, 20352056, https://doi.org/10.5194/amt-13-2035-2020, 2020.

Mikhailov, E., Vlasenko, S., Niessner, R., and Pöschl, U.: Interaction of aerosol particles composed of protein and saltswith water vapor: hygroscopic growth and microstructural rearrangement, Atmos. Chem. Phys., 4, 323-350, https://doi.org/10.5194/acp-4323-2004, 2004.

Mikhailov, E., Vlasenko, S., Martin, S. T., Koop, T., and Pöschl, U.: Amorphous and crystalline aerosol particles interacting with water vapor: conceptual framework and experimental evidence for restructuring, phase transitions and kinetic limitations, Atmos. Chem. Phys., 9, 9491-9522, https://doi.org/10.5194/acp-9-94912009, 2009.

Mikhailov, E. F., Vlasenko, S. S., and Ryshkevich, T. I.: Influence of chemical composition and microstructure on the hygroscopic growth of pyrogenic aerosol, Izv. Atmos. Ocean. Phy., 44, 416431, 2008.

Mochida, M. and Kawamura, K.: Hygroscopic properties of levoglucosan and related organic compounds characteristic to biomass burning aerosol particles, J. Geophys. Res.-Atmos., 109, D21202, https://doi.org/10.1029/2004jd004962, 2004.

Mulholland, G. W., Donnelly, M. K., Hagwood, C. R., Kukuck, S. R., Hackley, V. A., and Pui, D. Y. H.: Measurement of $100 \mathrm{~nm}$ and $60 \mathrm{~nm}$ particle standards by differential mobility analysis, J. Res. Natl. Inst. Stand. Technol., 111, 257-312, 2006.

Pruppacher, H. R. and Klett, J. D: Microphysics of clouds and precipitation, Kluwer Academic Publishers, Dordrecht, the Netherlands, 1997.

Rader, D. J. and McMurry, P. H.: Application of the tandem differential mobility analyzer to studies of droplet growth or evaporation, J. Aerosol Sci., 17, 771-787, 1986.

Raoux, S., Rettner, C. T., Jordan-Sweet, J. L., Kellock, A. J., Topuria, T., Rice, P. M., and Miller, D. C.: Direct observation of amorphous to crystalline phase transitions in nanoparticle arrays of phase change materials, J. Appl. Phys., 102, 094305, https://doi.org/10.1063/1.2801000, 2007.

Reid, J. P., Dennis-Smither, B. J., Kwamena, N.-O. A., Miles, R. E. H., Hanford, K. L., and Homer, C. J.: The morphology of aerosol particles consisting of hydrophobic and hydrophilic phases: hydrocarbons, alcohols and fatty acids as the hydrophobic component, Phys. Chem. Chem. Phys., 13, 15559-15572, 2011.

Rickards, A. M. J., Miles, R. E. H., Davies, J. F., Marshall, F. H., and Reid, J. P.: Measurements of the sensitivity of aerosol hygroscopicity and the $\kappa$ parameter to the O/C Ratio, J. Phys. Chem. A, 117, 14120-14131, 2013.

Romakkaniemi, S., Hämeri, K., Väkevä, M., and Laaksonen, A.: Adsorption of water on $8-15 \mathrm{~nm} \mathrm{NaCl}$ and $\left(\mathrm{NH}_{4}\right)_{2} \mathrm{SO}_{4}$ aerosols measured using an ultrafine tandem differential mobility analyzer, J. Phys. Chem. A, 105, 8183-8188, 2001.

Russell, L. M. and Ming, Y.: Deliquescence of small particles, J. Chem. Phys., 116, 311-321, 2002.

Sakurai, H., A. Fink, M., H. McMurry, P., Mauldin, R., F. Moore, K., N. Smith, J., and Eisele, F.: Hygroscopicity and volatility of 4-10 nm particles during summertime atmospheric nucleation events in urban Atlanta, J. Geophys. Res., 110, D22S04, https://doi.org/10.1029/2005JD005918, 2005.
Seinfeld, J. H., and Pandis, S. N.: Atmospheric Chemistry and Physics: From Air Pollution to Climate Change (Second edition), Wiley Interscience, New York, 2006.

Sihto, S.-L., Mikkilä, J., Vanhanen, J., Ehn, M., Liao, L., Lehtipalo, K., Aalto, P. P., Duplissy, J., Petäjä, T., Kerminen, V.-M., Boy, M., and Kulmala, M.: Seasonal variation of CCN concentrations and aerosol activation properties in boreal forest, Atmos. Chem. Phys., 11, 13269-13285, https://doi.org/10.5194/acp-11-132692011, 2011.

Stock, M., Cheng, Y. F., Birmili, W., Massling, A., Wehner, B., Müller, T., Leinert, S., Kalivitis, N., Mihalopoulos, N., and Wiedensohler, A.: Hygroscopic properties of atmospheric aerosol particles over the Eastern Mediterranean: implications for regional direct radiative forcing under clean and polluted conditions, Atmos. Chem. Phys., 11, 4251-4271, https://doi.org/10.5194/acp-11-4251-2011, 2011.

Su, H., Rose, D., Cheng, Y. F., Gunthe, S. S., Massling, A., Stock, M., Wiedensohler, A., Andreae, M. O., and Pöschl, U.: Hygroscopicity distribution concept for measurement data analysis and modeling of aerosol particle mixing state with regard to hygroscopic growth and CCN activation, Atmos. Chem. Phys., 10, 7489-7503, https://doi.org/10.5194/acp-10-7489-2010, 2010.

Su, H., Cheng, Y., and Pöschl, U.: New Multiphase Chemical Processes Influencing Atmospheric Aerosols, Air Quality, and Climate in the Anthropocene, Acc. Chem. Res., e16015301602983, https://doi.org/10.1021/acs.accounts.0c00246, 2020.

Tang, I. N.: Chemical and size effects of hygroscopic aerosols on light scattering coefficients, J. Geophys. Res., 101, 1924519250, 1996.

Tang, I. N. and Munkelwitz, H. R.: Composition and temperature dependence of the deliquescence properties of hygroscopic aerosols, Atmos. Environ. A-Gen., 27, 467-473, https://doi.org/10.1016/0960-1686(93)90204-C, 1993.

Tang, I. N. and Munkelwitz, H. R.: Water activities, densities, and refractive indices of aqueous sulfates and sodium nitrate droplets of atmospheric importance, J. Geophys. Res.-Atmos, 99, 18801$18808,1994$.

Tang, I. N., Fung, K. H., Imre, D. G., and Munkelwitz, H. R.: Phase transformation and metastability of hygroscopic microparticles, Aerosol Sci. Technol., 23, 443-453, 1995.

Tang, M., Chan, C. K., Li, Y. J., Su, H., Ma, Q., Wu, Z., Zhang, G., Wang, Z., Ge, M., Hu, M., He, H., and Wang, X.: A review of experimental techniques for aerosol hygroscopicity studies, Atmos. Chem. Phys., 19, 12631-12686, https://doi.org/10.5194/acp-1912631-2019, 2019.

Taylor, J. R. and Taylor, S. L. L. J. R.: Introduction To Error Analysis: The Study of Uncertainties in Physical Measurements, University Science Books, 1997.

Villani, P., Picard, D., Michaud, V., Laj, P., and Wiedensohler, A.: Design and validation of a volatility hygroscopic tandem differential mobility analyzer (VH-TDMA) to characterize the relationships between the thermal and hygroscopic properties of atmospheric aerosol particles, Aerosol Sci. Technol., 42, 729-741, 2008.

Wang, J., Krejci, R., Giangrande, S., Kuang, C., Barbosa, H. M. J., Brito, J., Carbone, S., Chi, X. G., Comstock, J., Ditas, F., Lavric, J., Manninen, H. E., Mei, F., Moran-Zuloaga, D., Pöhlker, C., Pöhlker, M. L., Saturno, J., Schmid, B., Souza, R. A. F., Springston, S. R., Tomlinson, J. M., Toto, T., Walter, D., Wim- 
mer, D., Smith, J. N., Kulmala, M., Machado, L. A. T., Artaxo, P., Andreae, M. O., Petäjä, T., and Martin, S. T.: Amazon boundary layer aerosol concentration sustained by vertical transport during rainfall, Nature, 539, 416-419, 2016.

Wang, L., Khalizov, A. F., Zheng, J., Xu, W., Ma, Y., Lal, V., and Zhang, R. Y.: Atmospheric nanoparticles formed from heterogeneous reactions of organics, Nat. Geosci., 3, 238-242, https://doi.org/10.1038/NGEO778, 2010.

Wang, X., Chen, C., Binder, K., Kuhn, U., Pöschl, U., Su, H., and Cheng, Y.: Molecular dynamics simulation of the surface tension of aqueous sodium chloride: from dilute to highly supersaturated solutions and molten salt, Atmos. Chem. Phys., 18, 1707717086, https://doi.org/10.5194/acp-18-17077-2018, 2018.

Wang, X., Lei, H., Berger, R., Zhang, Y., Su, H., and Cheng, Y.: Hygroscopic properties of $\mathrm{NaCl}$ nanoparticles on the surface: a scanning force microscopy study, Phys. Chem. Chem. Phys, 22, 9967-9973, 2020.

Wang, Z., Su, H., Wang, X., Ma, N., Wiedensohler, A., Pöschl, U., and Cheng, Y.: Scanning supersaturation condensation particle counter applied as a nano-CCN counter for size-resolved analysis of the hygroscopicity and chemical composition of nanoparticles, Atmos. Meas. Tech., 8, 2161-2172, https://doi.org/10.5194/amt8-2161-2015, 2015.

Wiedensohler, A., Cheng, Y. F., Nowak, A., Wehner, B., Achtert, P., Berghof, M., Birmili, W., Wu, Z. J., Hu, M., Zhu, T., Takegawa, N., Kita, K., Kondo, Y., Lou, S. R., Hofzumahaus, A., Holland, F., Wahner, A., Gunthe, S. S., Rose, D., Su, H., and Pöschl, U.: Rapid aerosol particle growth and increase of cloud condensation nucleus activity by secondary aerosol formation and condensation: A case study for regional air pollution in northeastern China, J. Geophys. Res.-Atmos., 114, D00G08, https://doi.org/10.1029/2008JD010884, 2009.

Wiedensohler, A., Birmili, W., Nowak, A., Sonntag, A., Weinhold, K., Merkel, M., Wehner, B., Tuch, T., Pfeifer, S., Fiebig, M., Fjäraa, A. M., Asmi, E., Sellegri, K., Depuy, R., Venzac, H., Villani, P., Laj, P., Aalto, P., Ogren, J. A., Swietlicki, E., Williams, P., Roldin, P., Quincey, P., Hüglin, C., Fierz-Schmidhauser, R., Gysel, M., Weingartner, E., Riccobono, F., Santos, S., Grüning, C., Faloon, K., Beddows, D., Harrison, R., Monahan, C., Jennings, S. G., O’Dowd, C. D., Marinoni, A., Horn, H.-G., Keck, L., Jiang, J., Scheckman, J., McMurry, P. H., Deng, Z., Zhao, C. S., Moerman, M., Henzing, B., de Leeuw, G., Löschau, G., and Bastian, S.: Mobility particle size spectrometers: harmonization of technical standards and data structure to facilitate high quality long-term observations of atmospheric particle number size distributions, Atmos. Meas. Tech., 5, 657-685, https://doi.org/10.5194/amt-5-657-2012, 2012.
Wiedensohler, A., Wiesner, A., Weinhold, K., Birmili, W., Hermann, M., Merkel, M., Müller, T., Pfeifer, S., Schmidt, A., Tuch, T., Velarde, F., Quincey, P., Seeger, S., and Nowak, A.: Mobility particle size spectrometers: Calibration procedures and measurement uncertainties, Aerosol Sci. Technol., 52, 146-164, 2018.

$\mathrm{Xu}$, B. and Schweiger, G.: In-situ Raman observation of phase transformation of $\mathrm{Na}_{2} \mathrm{SO}_{4}$ during the hydration/dehydration cycles on single levitated microparticle, J. Aerosol Sci., 30, S379S380, 1999.

Zhang, S. L., Ma, N., Kecorius, S., Wang, P. C., Hu, M., Wang, Z. B., Größ, J., Wu, Z. J., and Wiedensohler, A.: Mixing state of atmospheric particles over the North China Plain, Atmos. Environ., 125, 152-164, 2016.

Zhao, L.-J., Zhang, Y.-H., Wei, Z.-F., Cheng, H., and Li, X.H.:Magnesium sulfate aerosols studied by FTIR spectroscopy: hygroscopic properties, supersaturated structures, and implications for seawater aerosols, J. Phys. Chem. A, 110, 951-958, 2006.

Zheng, G. J., Duan, F. K., Su, H., Ma, Y. L., Cheng, Y., Zheng, B., Zhang, Q., Huang, T., Kimoto, T., Chang, D., Pöschl, U., Cheng, Y. F., and He, K. B.: Exploring the severe winter haze in Beijing: the impact of synoptic weather, regional transport and heterogeneous reactions, Atmos. Chem. Phys., 15, 2969-2983, https://doi.org/10.5194/acp-15-2969-2015, 2015.

Zheng, G., Su, H., Wang, S., Andreae, M. O., Pöschl, U., and Cheng, Y.: Multiphase buffer theory explains contrasts in atmospheric aerosol acidity, Science, 369, 1374-1377, 2020. 